Discussion

Papers

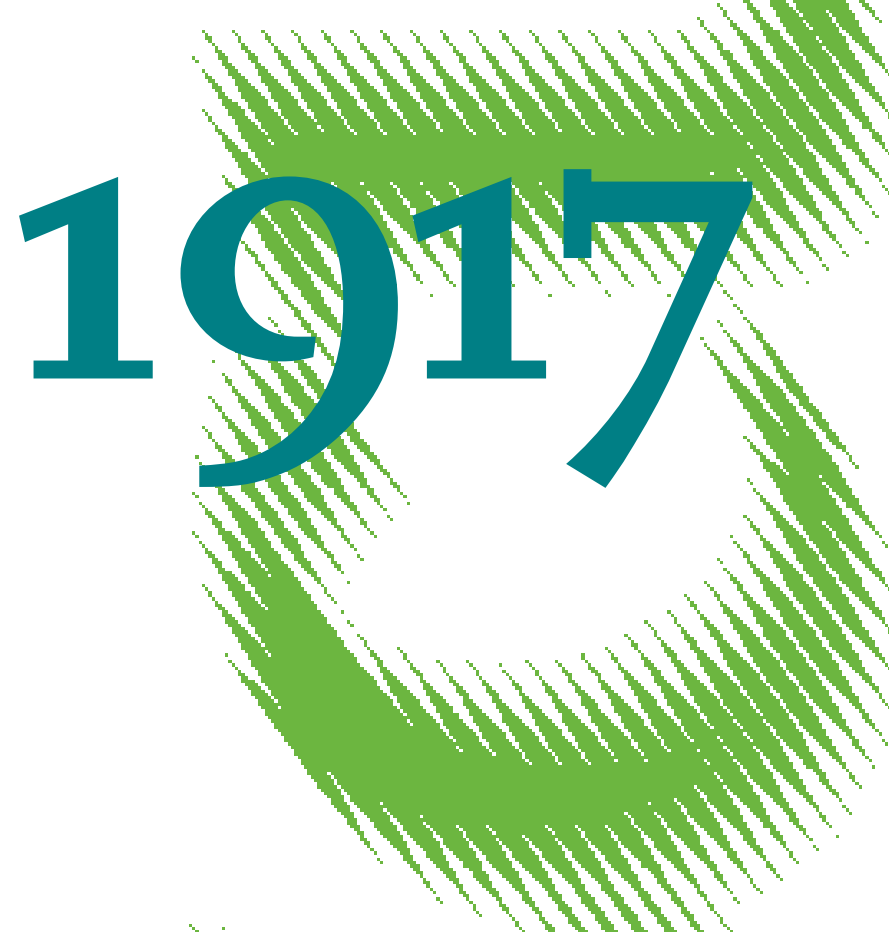

Corruption and Cheating: Evidence from Rural Thailand 
Opinions expressed in this paper are those of the author(s) and do not necessarily reflect views of the institute.

IMPRESSUM

(C) DIW Berlin, 2020

DIW Berlin

German Institute for Economic Research

Mohrenstr. 58

10117 Berlin

Tel. +49 (30) $89789-0$

Fax +49 (30) $89789-200$

http://www.diw.de

ISSN electronic edition 1619-4535

Papers can be downloaded free of charge from the DIW Berlin website:

http://www.diw.de/discussionpapers

Discussion Papers of DIW Berlin are indexed in RePEc and SSRN:

http://ideas.repec.org/s/diw/diwwpp.html

http://www.ssrn.com/link/DIW-Berlin-German-Inst-Econ-Res.html 


\title{
Corruption and Cheating: Evidence from Rural Thailand*
}

\section{Olaf Hübler ${ }^{\dagger} \quad$ Melanie Koch ${ }^{\ddagger}$ Lukas Menkhoff ${ }^{\S}$ Ulrich Schmidt $₫$}

November 2020

\begin{abstract}
This study tests the prediction that perceived corruption reduces ethical behavior. Integrating a standard "cheating" experiment into a broad household survey in rural Thailand, we find clear support for this prediction: respondents who perceive corruption in state affairs are more likely to cheat and, thus, to fortify the negative consequences of corruption. Interestingly, there is a small group of non-conformers. The main relation is robust to consideration of socio-demographic, attitudinal, and situational control variables. Attendance of others at the cheating experiment, stimulating the reputational concern to be seen as honest, reduces cheating, thus indicating transparency as a remedy.
\end{abstract}

JEL: O12 (micro analysis of economic development); D73 (...; corruption); D91 (... psychological, social factors on decision making)

Keywords: corruption; cheating; individual characteristics; lab-in-the-field experiment

*We thank participants at several seminars as well as Johannes Abeler, Eugen Dimant, Antonia Grohmann, and Menusch Khadjavi for helpful comments. Declarations of interest: none. Financial support by the German Research Foundation (DFG grant ME 1070/8) is gratefully acknowledged.

$\dagger$ Leibniz University Hannover, Königsworther Platz 1, D-30167 Hannover, Germany;

huebler@ewifo.uni-hannover.de

${ }^{\ddagger}$ Humboldt-Universität zu Berlin and German Institute for Economic Research (DIW Berlin), D-10108 Berlin, Germany; melanie.koch@diw.de

${ }^{\S}$ Humboldt-Universität zu Berlin and German Institute for Economic Research (DIW Berlin), D-10108 Berlin, Germany; Imenkhoff@diw.de

`Kiel Institute for the World Economy, Kiellinie 66, D-24105 Kiel, University of Johannesburg and University of Kiel, Germany; ulrich.schmidt@ifw-kiel.de. 


\section{Introduction}

Corruption is harmful for economies and due to its positive relationship to low per-capitaincome it hits developing economies stronger than advanced ones (Svensson, 2005). It fosters several kinds of activities that distract resources away from efficient production. There are numerous studies showing how costly these activities are (e.g. Olken and Pande, 2012). Thus, it is no surprise, and long established in the literature, that corrupt economies invest less and grow less than other economies (e.g. Mauro, 1995; Cieślik and Goczek, 2018). Moreover, corruption has negative effects on distribution (e.g. Hunt, 2007) and individual well-being (Sulemana et al., 2017).

In addition to these direct economic disadvantages, it is well documented that corruption detrimentally affects how a society functions, as it undermines the normative basis (for a comprehensive overview see Dimant and Tosato, 2018). Among others, it is argued that corruption contributes to a general decline of ethical behavior (e.g. Lambsdorff, 2007). The supposed mechanism is that people experience corrupt practices (either personally or through others), in particular by officials. This, subsequently, undermines their belief in norms in general and provides an example of seeking personal advantage over obeying societal norms. We argue and test empirically that this may lead to an outright increase in cheating behavior. Then, corruption feeds - via increased cheating behavior like a virus through all kinds of economic and social transactions.

The link between the level of corruption and cheating has, indeed, been shown by Gächter and Schulz (2016) in an innovative cross-country study. However, this countrylevel analysis by design cannot say much about causality and there is some concern that country characteristics may be the driving force. Thus, we complement this research and are the first - to our knowledge - to conduct an individual-level study on personally perceived corruption and cheating where we show the clear influence of corruption for a broader population while controlling for a large set of characteristics.

Accordingly, we integrate an item revealing perceived corruption (e.g. Kis-Katos and Schulze, 2013) as well as a standard cheating experiment, following Fischbacher and 
Föllmi-Heusi (2013), into a household survey of about 500 participants in Thailand. Embedding the question and the experiment in a household survey ensures that we can control for extensive individual and household information. Additionally, Thailand is plagued by a high level of corruption (however, still at a conventional level for emerging economies such as Brazil or China, see World Bank (2018); Svensson (2005)), which makes it an interesting study site (see also Phongpaichit and Phiriyarangsan, 1996).

We find that the perception of prevalent corruption and cheating are positively related, suggesting that perceived corruption in state affairs influences individual cheating. This holds for the overwhelming majority (more than $93 \%$ of participants), which we analyze in more detail, while a small group responds honestly despite perceiving a high degree of corruption. In all cases, corruption is reasonably regarded the exogenous driver as it is based on the observation of society, while cheating is an individual decision, which makes reverse causality unlikely. Moreover, direct motivated beliefs or biases like the false consensus effect can largely be excluded because perceived corruption is elicited in an indirect way and, in particular, in an earlier survey wave, i.e. one year before the cheating experiment takes place. In order to reveal the influence of corruption on cheating, we control for a large set of potentially confounding factors. Finally, we confirm the impact of corruption on cheating in an IV-estimation. Despite these arguments and facts, we cannot completely rule out that there is also reverse causality in that individuals who tend toward cheating may more often believe that the government is corrupt.

According to Abeler et al. (2019), two kinds of underlying preferences are necessary to explain the observed behavior of a limited degree of cheating theoretically, i.e. a preference for being honest and an individual's preference for an honest reputation. Reputation seems to be at stake if other persons observe the outcome of the experiment and, thus, an element of suspicion of cheating is induced (Kajackaite and Gneezy, 2017). We directly test this implication of "reputational concerns" by allowing others to be present when starting the household survey; the experiment is conducted at a later stage of the questionnaire. Thus, attendance is decided before the experiment, the content of which is unknown to 
the participants ex ante and, therefore, largely exogenous; we analyze this deeper in the robustness section. We confirm the theoretically expected negative relationship, i.e. if there are attendants, the degree of cheating is reduced. This result supports the internal validity of our field experiment. It also has a policy implication by emphasizing the helpful role of transparency, which is relevant in fighting corruption (Vadlamannati and Cooray, 2017). Furthermore, it cautiously indicates that also other policies against corruption may directly work against general cheating behavior, such as rule of law (Jetter and Parmeter, 2018), monitoring (Gans-Morse et al., 2018), and improved information (Kuecken and Valfort, 2019).

In modeling the relation between corruption and cheating, we first separate the aforementioned small group that responds honestly despite perceiving high corruption. Second, we show that relations of interest are revealed more precisely if a regression model with weights is used, where groups of respondents with a higher probability of cheating receive lower weights. The reason is that these groups consist of cheaters and non-cheaters, which makes the summary information difficult to allocate to either subgroup. In contrast, the information of a group with hardly any cheaters clearly belongs to non-cheaters. When we omit this weighting and either use sampling weights for all groups of respondents or use an interval regression or an ordered logit model, coefficients point in the same direction and keep their relative importance, but the standard errors are higher, turning many coefficients insignificant (as we show in the robustness section). Thus, employing a weighted regression model may be particularly helpful for samples that are relatively small or noisy.

While these findings on the influence of corruption on cheating at the individual level are new to the literature - to the best of our knowledge - it is crucial that they are based on a conventional sample (in parallel work Ajzenman, 2020 analyzes a very similar idea for students). Our experiment is set in a relatively poor area of rural Thailand, meaning that - given the comparatively high stakes of our experiment - the opportunity cost of honesty (i.e. not cheating) are high. However, it is reassuring that our sample, by and 
large, reproduces five stylized facts (see Abeler et al., 2019) as we show in the following section.

Literature. Our research relates to four strands of literature: (i) the deteriorating effects of corruption; (ii) the relation of corruption and cheating; (iii) differences in the degree of cheating across countries; and (iv) the relation of cheating to socio-demographic characteristics, individual attitudes, or situational characteristics of the experiment.

(i) While it is in principle possible that corruption may motivate otherwise inactive government officials, empirical evidence does not find that this effect dominates the negative consequences of corruption. By contrast, macro-studies and micro-studies reveal large costs (e.g. Olken and Pande, 2012; Fisman and Golden, 2017). At the macro level, corruption leads to lower investment and growth (e.g. Mauro, 1995; Cieślik and Goczek, 2018). At the micro level, there are various channels by which corruption reduces welfare. These channels include increased rent seeking (e.g Lambsdorff, 2007), investment in political connections (e.g. Lehne et al., 2018), distorted firm decisions (e.g Sequeira and Djankov, 2014), failure to correct externalities (e.g. Bertrand et al., 2007), and distorted provision of public goods (see the discussion in Kis-Katos and Schulze, 2013, p.84f.). We contribute by showing an influence of corruption on increased cheating behavior at the individual level.

(ii) According to our knowledge, there is no study examining the relation between cheating and perceived corruption as we do within a household survey, but there are studies related to ours. Closest to us are Gächter and Schulz (2016) as they conduct the same experiment as we do in 23 countries and find that lying is more prevalent in countries where rule violations, including corrupt practices, are more prevalent. However, they are not analyzing the effect of individually perceived corruption on cheating but the prevalence of corruption at the country level. Houser et al. (2012) find that cheating is stronger after previously being treated unfairly and corruption certainly has an element of unfairness. Ajzenman (2020) studies a similar effect to ours, i.e. the effect of corruption on cheating in school exams (i.e. cheating measure and sample are different from our 
research) and finds a significant positive effect. In a similar manner, Drupp et al. (2019) find that persons tend to lie more if they face a regulator who they deem ill-regarded. Thus, as already noted, corruption might change the perception of norm violations. A related strand of the literature analyzes how motivated (distorted) beliefs about social norms subsequently lead or are used to justify more deviant behavior (e.g. Di Tella et al., 2015; Gneezy et al., 2020; Bicchieri et al., 2020).

(iii) Empirical studies on cheating focus mainly on advanced economies, using students and lab experiments (see Abeler et al., 2019). From this perspective, we analyze a rare sample, as we cover a relatively poor rural population in a field setting. However, multicountry studies do not find major differences regarding the degree of cheating across countries (e.g. Mann et al., 2016; Abeler et al., 2019). Regarding the specific country, i.e. Thailand, we are only aware of one other study. Boonmanunt et al. (2020) analyze how scarcity, especially in interaction with social norms, affects cheating behavior of Thai farmers from the same region as we analyze. They conclude that scarcity itself has no effect on the prevalence of cheating but that social norms lead to less cheating only in times of abundance. Similarly, Aksoy and Palma (2019) find no effect of scarcity on cheating for Guatemalan coffee farmers. Still, although the evidence is mixed and seems task dependent (see Kajackaite and Gneezy, 2017), the meta-study of Abeler et al. (2019) shows that cheating slightly increases with higher incentives. Noteworthy, Cohn et al. (2019) find in their multinational study that honesty increases with stakes. However, the task on civic honesty is not directly comparable to our cheating game. In comparison to Boonmanunt et al. (2020) the expected payoff in our game is more than twice as large (not adjusted for inflation) and, indeed, the degree of cheating in our experiment is slightly higher (around 30\% vs. 20\%).

(iv) The meta-study of Abeler et al. (2019) on cheating focuses on the self-reported outcome format as we do in our study. It finds that being male is the only socio-demographic variable robustly related to cheating (see also the representative study of Abeler et al., 2014), while age seems to be tentatively related to less cheating. 
Moreover, there is an extensive literature relating cheating to attitudes or situational circumstances, which we address here selectively. For example, risk tolerance can be connected to more cheating (Gino and Ariely, 2012). Some studies discuss implications when cheating has potential effects on other persons (e.g. Butler et al., 2016). Finally, our test of reputational concerns via attendance of others can be interpreted as a kind of monitoring that is known to tentatively reduce cheating (see Gneezy et al., 2018; Rilke et al., 2019). Overall, we aim for considering these determinants as control variables.

Our study is organized in five more sections. Section 2 describes the survey, the perceived corruption item, and the standard cheating experiment, while Section 3 develops expectations about the relation between cheating and individual or situational characteristics. Respective results are reported in Section 4. Section 5 provides several robustness tests, and Section 6 concludes.

\section{Survey, perceived corruption, and cheating experi- ment}

This section provides a short description of the survey and the sample population (Section 2.1), responses to the items revealing perceived corruption (Section 2.2), the implementation and outcome of the cheating experiment (Section 2.3), and the relation between corruption and cheating (Section 2.4).

\subsection{About the household survey}

The basis of our research is a large household survey in northeast Thailand (the Thailand Vietnam Socio-economic Panel) conducted about every two years since 2007 (see e.g. Hardeweg et al., 2013). A total of three provinces in Thailand are covered. A three-stage sampling procedure is applied in order to representatively cover rural households in this area. We use 2013 survey data to obtain comprehensive information on individuals and their households, but only from the province of Ubon Ratchathani. We then conduct 
our lab-in-the-field experiment with these 860 individuals/households one year later. As connecting the data at the individual level over the two years is sometimes not possible, we use a reduced sample of still more than 500 individuals (between 18 and 85 years) for whom experimental results and individual information is available; we call this the "full information" sample. However, there are no major economic differences between the full and the reduced information sample, as we show below.

Descriptive statistics on socio-demographic characteristics of our main population, where full information is available, are provided in Table 1. Men make up $35 \%$ of the sample and participants are on average 55 years old. Education is limited as participants have an average of 5.5 years of schooling. The consumption and asset figures are household information, as this is the relevant economic unit. As consumption - relative to income - can provide more reliable and useful information in poor rural areas, we rely on this variable. The lower part of the table provides information about additional variables that are introduced in Section 3. We show the same descriptive information, first, for those 335 participants where we only have information about the experiment (these observations have to be neglected in the following), and, second, for the full information sample. The last column shows that differences between the two sub-samples with "full information" and "only experiments" are not very strong, so that we are not concerned about the representativeness of our estimation sample.

[Table 1 about here]

\subsection{Question and descriptive result on perceived corruption}

Perceived corruption is derived from the answers to the survey question "There could be many reasons why not all government money reaches the targeted poor households. Which of the following do you think are the two main reasons why money may not reach the poor?" Survey participants can choose two main reasons without ranking them from the following four alternatives: "government procedures are expensive," "government officers are inefficient," "corruption," and "don't know." We acknowledge that there may be some 
overlap between the response categories, because inefficient or corrupt governments also offer expensive services. Still, the categories each have a clear focus and "corruption" is just one reason for expensive or inefficient services. Additionally, all categories are presented before participants give an answer such that the focus is even clearer.

There is valid concern that individually perceived corruption is a flawed measure of actual corruption because of personal biases or lacking knowledge about corrupt practices (Olken, 2009). However, given our research question, we explicitly care about the personal perception of each individual even if it may differ from the actual prevalence of corruption. Our measure also purposely differs from widely used corruption indices which are usually constructed by asking country experts and leading business people about their perception. It seems likely that the corruption experience and thereby the perception of village people in rural Thailand differ from those in the former group.

A further concern that arises with the use of individual perceptions is reverse causality because of, for example, the false consensus effect or confirmation bias. Respondents who cheat themselves could perceive corruption to be prevalent as they judge others by their own standards. We try to reduce this concern by not asking explicitly about the prevalence of corrupt practices or the share of corrupt government officials but taking a more indirect turn with the question as stated above. Moreover, we ask for perceived corruption one year before we conduct the cheating experiment, which makes reverse causation unlikely (see Figure 1). This is a crucial advantage as there is recent empirical evidence showing that people strategically distort beliefs about the wrong-doing of others at least in the cheating task if they know that they will perform the task themselves later in that session and, thus, have an opportunity to cheat as well (see Bicchieri et al., 2020). Importantly, there were no specific anti-corruption policies or scandals between the two years, such that perceived corruption is assumed to be stable. Noteworthy, only several weeks after our survey took place in 2014, the coup d'état happened with the military junta subsequently declaring a war against corruption.

[Figure 1 about here] 
Thus, we believe that the aforementioned survey question is useful for our research question. We define our measure of perceived corruption as a dummy variable, i.e. respondents mention the corruption item as either a first or second main reason. Such a response applies to $75 \%$ of respondents.

\subsection{Implementation and descriptive result of the "cheating exper- iment"}

The cheating experiment follows the example of Fischbacher and Föllmi-Heusi (2013). It is carried out by the interviewer, who conducts the entire interview, including experiments on risk attitude measured with a multiple price list (see Appendix Table B.1), time preferences measured with a multiple price list as well, the cheating experiment (at third place), and a newly established game to measure inequality aversion. In order to keep the whole survey feasible, the order and instructions are always the same, and we neither change incentives, nor repeat the experiment (for the instructions see Appendix A). At the end of the complete interview, one of the four experiments is randomly selected for payout. The expected payoff varies across these four experiments but is always on the order of 100 to 150 Thai Baht (i.e. about 3 to 5 US-Dollar at that time or 9 to 14 USDollar at purchasing power parity). In addition, there is a participation fee of 30 Baht, which is equivalent to the price of a regular meal. As the total interview takes about one hour, participation is attractive from a financial perspective. The theoretically expected payoff of 125 Baht equals almost a half-day wage for an unskilled laborer in that area of Thailand at that time. We do not have reason to believe that the other games impacted the relation between corruption and cheating behavior in any direction. The fourth game was not disclosed before it was played and the choices in the multiple price lists for risk and time preferences are not related to perceived corruption.

The cheating experiment starts with the interviewer briefly explaining the experiment and providing the subjects, one from each household, a six-sided die with numbers one to six and a box. Then, the payoff table is shown to the subject and the payoff is explained, 
i.e. number one gets 50 Baht, number two gets 100 Baht until number five which gets 250 Baht, while number six gets zero Baht. The expected payoff under the assumption of a fair-sided die is 125 Baht (750 divided by 6), thus providing an incentive for cheating behavior (Martinelli et al., 2018). Thereafter, the interviewer asks the subject to secretly roll the die several times in the box, to keep the first number rolled in mind, and to report this at the end to the interviewer, who then takes note of the outcome. For the subsequent analysis, we will order the die rolls by their payoffs, which means number 6 is recoded as the number 0 in the analysis.

Each number has the same probability of being rolled, i.e. $16.7 \%$. However, people do not report such an equal distribution of outcomes, as we know from thousands of participants in earlier experiments. Indeed, the pattern of our responses is quite conventional as shown in Figure 2.

[Figure 2 about here]

Moreover, the outcomes for our sample are reassuring as they largely confirm five well known stylized facts (Abeler et al., 2019). The outcomes for our sample are presented in the left part of Figure 3, separately for women and men. It is obvious (stylized fact i) that participants do cheat, (ii) that the second-best outcome is also over-represented, (iii) that the degree of cheating is limited (about 30\% of the maximum), and (iv) that men cheat more than women. The right part of Figure 3 shows responses as compiled by the meta-study; comparing the left and right parts of Figure 3, one can see the very nice fit of our experiment into the pattern of earlier experiments. While we find a negative relation between cheating and age only until the age of 50 (thus only partial accordance with stylized fact v), the first four facts clearly indicate that behavior in our sample is regular and, hence, further examinations can be largely generalized.

[Figure 3 about here]

A concern regarding the use of this experiment in a poor rural area is that participants may misunderstand the payoffs, in particular, if they claim to have rolled a 6 (with 
no payoff). There are four facts that stand against such an interpretation: first, we did a test run prior to the regular experiment, without any indication of misunderstanding. Furthermore, as can be seen in the instructions (see Appendix A), the payoff table was shown to the participants such that they could see that rolling a six corresponds to zero payoff. Third, the experiment chosen has become an accepted standard in the literature. Interestingly, the outcome with our sample regarding the frequency reporting a 6 is basically the same as for the world average (see Figure 3). Fourth, there is no difference in the educational level between those rolling the 6 and others as shown below (see 2). We have extended this comparison to a test of numeracy but again there is no difference $(\mathrm{p}=0.554)$. Despite these four facts against a misunderstanding of the payoffs, we cannot completely rule out this possibility.

[Figure 4 about here]

\subsection{The relation between perceived corruption and cheating}

The bivariate relation between the share of perceived corruption (a dummy variable, here, relative to the average) and the degree of cheating is shown in Figure 4. By-and-large, there is a positive relation, i.e. a larger share of perceived corruption is related to a higher degree of cheating. However, the first group, i.e. those receiving a pay-off of zero, seems to be different from the others. While the expected pattern holds nicely for die rolls from 1 to 5 , this relation breaks down for those saying that they roll a 6 and get a payoff of 0 . There is a group of people, who, despite perceiving a large amount of corruption, decide for themselves to stay honest. Thus, they seem to draw a different conclusion about perceived corruption than does the vast majority. It could be a form of resistance or they might want to counteract the wrongdoing of their political leaders or want to feel morally superior to others because of self-image concerns. It seems noteworthy that these individuals do not compromise even when they perceive corruption. Even more so, they seem to defy. This group is probably larger than the share we can identify within the 
sample, as there may be others who rolled lower numbers but would also report the truth had they had rolled a 6.

The question is how to continue the analysis given this "non-linearity" in the relationship between corruption and cheating. Simply ignoring the break in the relationship of interest does not do justice to the data; a linear regression including all participants shows an insignificant relation which is misleading for 93 percent of the sample (see Appendix Table D.2). Thus, we test a two-step decision model, where the first step is that perceived corruption leads to either less or more cheating. The problem with this approach is that the observed characteristics of those who report having rolled a 6 are not much different from the others (see Table 2). Moreover, we do not observe variation among those who cheat less. Overall, this modeling approach does not seem appropriate in our case. As our initial hypothesis revolves around corruption and cheating, we continue our analysis with focusing on the vast majority of observations that definitely include cheaters, given the frequencies of certain die rolls. We exclude those individuals having rolled a 6 , i.e. those who show no cheating with a very high probability, although they perceive corruption to a relatively high degree. Thus, we acknowledge as our first finding that there seems to be a fraction of people for whom the relationship between corruption and cheating is different from the majority.

[Table 2 about here]

\section{Expectations about potentially covarying character- istics}

In this section, we develop ex ante hypotheses about characteristics that may be related to cheating and, thus, should be controlled for when analyzing the relation between corruption and cheating (Section 3.1). The variables measuring these characteristics are discussed in Section 3.2. 


\subsection{Hypotheses about the role of covarying characteristics}

We take advantage of our survey covering various items to consider a range of possible covariates. For socio-demographic characteristics, we expect, in line with the meta-study of Abeler et al. (2019), (i) that men will cheat more than women (e.g. Houser et al., 2012), (ii) a slightly negative relation between cheating and age, (iii) a kind of ambiguous relation may apply to education, and (iv) the relation of cheating to consumption (or income) is potentially ambiguous as well (for more details see Appendix B).

Beyond these socio-demographic characteristics, there may be four individual attitudes or situational characteristics that are related to cheating; the exact survey items are introduced in Section 3.2.

(v) Risk-taking: we argue that cheating may require an element of going against societal norms and this may be easier for risk tolerant individuals. Moreover, we include risk-taking, although Abeler et al. (2014) do not find a relation in their telephone-based cheating task, because this non-relation is potentially task- or situation-dependent. In our setting, respondents are physically facing the interviewer, which might be perceived as more risky than lying on the telephone. Furthermore, since attendants are allowed at the scene, risk tolerance might play a role in judging if others detect cheating or not.

(vi) Confidence: we hypothesize that confident individuals believe in their ability, including earning money, and, thus, are less reliant on cheating as a way to gain a (financial) advantage. In this sense, confident individuals can afford to be more honest than others.

(vii) Trust in other people: the expectation is that individuals who trust others more, will cheat less, as trust relies on the belief that others do not cheat (see Butler et al., 2016). We would like to mention that not all referees regard the variables confidence and trust as ex ante useful to be included in the analysis.

(viii) The number of attending people, excluding the interviewer and participant, is analyzed, because people care about their reputation to be honest Abeler et al. (2019). The argument here is that others present during the experiment may doubt the highest outcome, such that participants may shy away from cheating if there are observers. 


\subsection{Description of individual attitudes and situational character- istic}

In this section, we describe the measurement and distribution of the three aforementioned attitudes above as well as the number of people attending the experiment.

Risk taking. Risk taking is measured by a multiple price list (MPL) following the approach of Holt and Laury (2002). A 50:50-lottery between 0 and 300 THB is fixed while the safe amount is increasing from 0 to 190 THB. The outcome of this question is presented in Figure B.2. The explanatory power of this measure is shown for an earlier wave of this household survey in Hardeweg et al. (2013).

Confidence. Here, we rely on the question whether participants feel confident when they make an agricultural decision. The question intentionally refers to a concrete field of decision making. Agriculture is the best choice in this respect because the survey takes place in a rural area. Accordingly, almost all participants have some experience in agriculture, at least for the purpose of subsistence production. The coding ranges from 1 for being "always confident" to 5 for being "never confident." The distribution of answers is shown in Figure B.3. Most people have a mild level of confidence, with extreme values reported by a few participants.

Trust in other people. We use a survey item that asks how much respondents "trust people outside the own village." The distribution is depicted in Figure B.4. As higher numbers indicate more trust, the clear majority of respondents expresses no or little trust in strangers from outside their own village.

Number of attendants. One last piece of information that the interviewers note is the number of people attending the interview (excluding interviewer and the participant); this occurs at the point of time when our experiment is conducted. Attendance of others can happen because the interview takes place in the household's dwelling and there are either household members or guests around as the dwellings are usually open. This makes it practically impossible to randomly vary attendance. It is important to highlight that the nature of the experiment is not announced in advance. Accordingly, there is no strong 
concern of an endogenously determined number of attendants (an issue we investigate further in robustness Section 5). Figure 5 provides simple descriptive statistics of how many people are present at the time the experiments are conducted. As shown (see also the descriptive statistics in Table 1), there are attendants in $65 \%$ of cases and the average number, conditional on the case of attendance, exceeds two persons. This number is 2.15 for women and 2.28 for men, the difference is not statistically significant (two-sided t-test, $\mathrm{p}=0.5)$.

[Figure 5 about here]

\section{Empirical approach and results}

We report results in three steps. First, Section 4.1 introduces the empirical approach for the multivariate analysis, Section 4.2 contains the main results, and Section 4.3 complements these with further analyses.

\subsection{Empirical approach}

Our dependent variable of "cheating" is a discrete ordered variable. We know that this variable is neither uniformly nor normally distributed, with specific numbers mentioned more frequently than others (see Section 2.3). As we exclude the group with a payoff of zero (see Section 2.4), higher payoffs also mean that these groups cheat with a higher probability than others. Thus, first, due to the incentives provided, these groups are larger than others; second, the information about non-cheating vs. cheating is less precise as these groups increasingly comprise non-cheaters and cheaters. Consequently, overweighting the groups with lower payoffs relative to the higher payoff groups corrects for the explained distortions.

Thus, we conduct estimates weighted by the inverse difference between observed and theoretical frequencies in each category, standardized by the share of honest persons. More 
details on how this procedure is implemented here are provided in Appendix C. The important insights are, first, that this procedure is more convincing from an economic point of view than the alternatives and, second, that applying the weighting approach is helpful for revealing the influence of corruption on cheating more precisely, as we demonstrate in robustness testing in Section 5.

\subsection{Explaining cheating behavior: main results}

We now apply the multivariate weighting approach to our variables of interest, as introduced by the hypotheses in Section 3.1. In order to limit the number of variables, we rely on the consumption variable but omit asset variables as information in these variables is clearly correlated. Column (1) of Table 3 presents the full specification with all considered variables, of which four are statistically significant at the $5 \%$ level. We shortly discuss these outcomes:

[Table 3 about here]

(i) Our main variable of interest, i.e. perceived corruption, is positively related to cheating. The coefficient is highly significant. On average, perceiving corruption increases the reported die number by 0.33 ; about 0.25 of the standard deviation.

(ii) Age has a non-linear relation with cheating. In line with the literature, cheating declines with age (significant at the $5 \%$ level); however, older people in our sample, i.e. those beyond about 50 years old, cheat more with higher age, and this effect is significant at the $5 \%$ level as well.

(iii) A larger number of attendants decreases the degree of cheating, significantly at the $5 \%$ level. This means that playing the game while others observe the participants reduces the probability of cheating. This is consistent with the model of Abeler et al. (2019).

Finally, we would like to mention that most of the statistically insignificant coefficients have the expected sign: the coefficients of male and risk-taking are positive, the one on 
trust is negative - all as expected; only the positive coefficient on confidence contradicts the hypothesis. The coefficients on education and consumption were ex ante undetermined and are positive.

The model of Abeler et al. (2019) contains two preferences to explain observable cheating behavior, i.e. a "preference for honesty" and a "preference for reputation to be seen as honest." While the latter preference, i.e. to be seen as honest, seems to be confirmed by the negative effect of number of attendants, perceived corruption can be linked nicely to the preference for honesty: a higher degree of perceived corruption means that although laws are violated the perception of honesty being a social norm shifts and, hence, tends to undermine honest behavior.

\subsection{Further analyses}

In further columns, we dig deeper into the potential determinants of cheating. In column (2) of Table 3, we consider the total value of assets a household has (as substitute for consumption) and, as can be seen, having more valuable assets is significantly and negatively related to cheating. Column (3) shows a regression where we take the former specification (1) but substitute the number of attendants with a binary variable indicating whether there are any attendants or not. Results remain almost unchanged. In all specifications, the remaining coefficients are largely unaffected. In column (4), we show that the above main findings also hold when only the so far significant variables $(\mathrm{p}<0.1)$ are considered. The coefficient on the corruption variable increases, while for most other coefficients their sizes and their level of statistical significance change only slightly. However, the asset value turns insignificant.

In column (5), we employ an IV-approach. As the variable "perceived corruption" is measured with an individual assessment, it is possible that there is reverse causality, especially if cheating behavior is time-invariant. Those individuals who tend toward cheating possibly believe with a higher probability than others that the government is corrupt. Therefore, we repeat our main specification from column (1) by applying an 
instrumental variable estimation. As we are not aware of an instrument for corruption within our dataset, we employ a purely econometric approach generating an instrument as proposed by Lewbel (2012), an approach with a rising number of applications (e.g. Grohmann et al., 2018). The result is qualitatively in line with earlier regression results. Hansen's J statistic $(\mathrm{J}=11.1$ with $\mathrm{p}=0.199)$ shows that the overidentifying restriction is valid because of $\mathrm{p}>0.05$. The null hypothesis that the instruments are valid cannot be rejected.

Overall, we consider a set of variables that are related to cheating behavior and, thus, should ideally be controlled for when analyzing the relation between corruption and cheating behavior.

\section{Robustness tests}

In the robustness section, we address four issues. While full results of these tests are shown in Appendix D, we present main results of the robustness tests here. First, different empirical models are implemented which are consistently applied to our main regression, i.e. specification (1) in Table 3: we use different weights and three further standard estimation approaches. All results confirm the main finding and indicate that weighted estimates are superior to alternatives (Subsection D.1). Furthermore, we show that an OLS regression including all observations does not reveal the effect of interest. Second, we analyze cheating behavior by defining different forms of cheating behavior, i.e. we modify the LHS-variable (Subsection D.2). Third, we define perceived corruption differently, i.e. we modify the RHS-variable (Subsection D.3). Re-defining our two main variables does not give further insights into the relationship between corruption and cheating. Fourth, we split the sample regarding whether there were attendants at the cheating experiment or not (Subsection D.4). Here, we find that especially risk aversion seems to mediate the effect of attendants. 


\section{Conclusion}

Corruption is harmful for every society and its economy. Not only does it reduce growth, it also worsens how societies function as it undermines their normative basis. This has manifold negative effects, also beyond reduced growth, and is, thus, of great concern. One of these potential negative effects is that corruption may lead to increased cheating. This relation has been shown in a cross-country study, relying on the standard cheating experiment by Fischbacher and Föllmi-Heusi (2013). We contribute to the literature by examining this relation for the first time at the individual level within a broader population. This does not only deepen the analysis by controlling for numerous potentially covarying characteristics but also allows for a more causal interpretation.

Specifically, we assess perceived corruption of individuals and conduct a standard labin-the-field cheating experiment with the same individuals one year later. The study is conducted in a setting where corruption plays a large role, i.e. in rural Thailand. In order to demonstrate that results from this study may be generalizable, we largely reproduce five stylized facts found in a wealth of studies on cheating. Thus, we seem to have a reliable basis supporting that our novel research helps to better understand the deteriorating effects of corruption beyond just the specific sample.

We find that perceived corruption is strongly and robustly related to more cheating while controlling for a wide range of socio-demographic, attitudinal, and situational characteristics. Thus, we consider a large set of potentially confounding determinants of cheating. These determinants also incorporate the theoretical set-up of Abeler et al. (2019), that a preference for honesty and a preference for being seen as honest are necessary to explain observable behavior. Honesty seems to be undermined by perceived corruption. However, it seems to be supported by the attendance of other people at the cheating experiment, most probably by increased reputational concerns, and to some degree by a medium age.

The policy consequences of these findings appear straightforward. Any measure that succeeds in fighting corruption will probably positively affect honest behavior in the pop- 
ulation (see discussion in Svensson, 2005 and evidence in Dell'Anno, 2020). This effect may not just hold in the experiment but plausibly also in other domains and in real world behavior in general, acknowledging that experimentally revealed cheating predicts real world behavior (see, e.g., Hanna and Wang, 2017). Moreover, transparency of decision processes, here approximated by attendants in the experiment, seems to help support honest decision making: it may spur reputational concerns and impede corrupt practices. 


\section{References}

Abeler, Johannes, Anke Becker, and Armin Falk, 2014, "Representative evidence on lying costs." Journal of Public Economics, 113, 96-104.

Abeler, Johannes, Daniele Nosenzo, and Collin Raymond, 2019, "Preferences for truth-telling." Econometrica, 87 (4), 1115-1153.

Ajzenman, Nicolás, 2020, "The power of example: corruption spurs corruption." American Economic Journal: Applied Economics. Forthcoming.

Aksoy, Billur and Marco A. Palma, 2019, "The effects of scarcity on cheating and in-group favoritism." Journal of Economic Behavior and Organization, 165, 100 - 117.

Bertrand, Marianne, Simeon Djankov, Rema Hanna, and Sendhil Mullainathan, 2007, "Obtaining a driver's license in India: an experimental approach to studying corruption." The Quarterly Journal of Economics, 122 (4), 1639-1676.

Bicchieri, Cristina, Eugen Dimant, and Silvia Sonderegger, 2020, "It's not a lie if you believe the norm does not apply: conditional norm-following with strategic beliefs." Working Paper.

Boonmanunt, Suparee, Agne Kajackaite, and Stephan Meier, 2020, "Poverty negates the impact of social norms on cheating." Working Paper.

Butler, Jeff, Paola Giuliano, and Luigi Guiso, 2016, "Trust and cheating." The Economic Journal, 126 (595), 1703-1738.

Cieślik, Andrzej and Łukasz Goczek, 2018, "Control of corruption, international investment, and economic growth - evidence from panel data." World Development, 103, 323 - 335.

Cohn, Alain, Michel André Maréchal, David Tannenbaum, and Christian Lukas Zünd, 2019, "Civic honesty around the globe." Science, 365 (6448), 70-73.

Dell'Anno, Roberto, 2020, "Corruption around the world: an analysis by partial least squaresstructural equation modeling." Public Choice, 184 (3), 327-350.

Di Tella, Rafael, Ricardo Perez-Truglia, Andres Babino, and Mariano Sigman, 2015, "Conveniently upset: avoiding altruism by distorting beliefs about others' altruism." American Economic Review, 105 (11), 3416-42. 
Dimant, Eugen and Guglielmo Tosato, 2018, "Causes and effects of corruption: what has past decade's empirical research taught us? A Survey." Journal of Economic Surveys, 32 (2), 335-356.

Drupp, Moritz A., Menusch Khadjavi, and Martin F. Quaas, 2019, "Truth-telling and the regulator. Experimental evidence from commercial fishermen." European Economic Review, 120, 103310.

Fischbacher, Urs and Franziska Föllmi-Heusi, 2013, "Lies in disguise - an experimental study on cheating." Journal of the European Economic Association, 11 (3), 525-547.

Fisman, Raymond and Miriam A. Golden, Corruption: what everyone needs to know, Oxford University Press, 2017.

Gächter, Simon and Jonathan F. Schulz, 2016, "Intrinsic honesty and the prevalence of rule violations across societies." Nature, 531 (7595), 496-499.

Gans-Morse, Jordan, Mariana Borges, Alexey Makarin, Theresa Mannah-Blankson, Andre Nickow, and Dong Zhang, 2018, "Reducing bureaucratic corruption: interdisciplinary perspectives on what works." World Development, 105, $171-188$.

Gino, Francesca and Dan Ariely, 2012, "The dark side of creativity: original thinkers can be more dishonest." Journal of Personality and Social Psychology, 102 (3), 445.

Gneezy, Uri, Agne Kajackaite, and Joel Sobel, 2018, "Lying aversion and the size of the lie." American Economic Review, 108 (2), 419-53.

Gneezy, Uri, Silvia Saccardo, Marta Serra-Garcia, and Roel van Veldhuizen, 2020, "Bribing the self." Games and Economic Behavior, 120, 311 - 324.

Grohmann, Antonia, Theres Klühs, and Lukas Menkhoff, 2018, "Does financial literacy improve financial inclusion? Cross country evidence." World Development, 111, 84-96.

Hanna, Rema and Shing-Yi Wang, 2017, "Dishonesty and selection into public service: evidence from India." American Economic Journal: Economic Policy, 9 (3), 262-90.

Hardeweg, Bernd, Lukas Menkhoff, and Hermann Waibel, 2013, "Experimentally validated survey evidence on individual risk attitudes in rural Thailand." Economic Development and Cultural Change, 61 (4), 859-888.

Holt, Charles A. and Susan K. Laury, 2002, "Risk aversion and incentive effects." American Economic Review, 92 (5), 1644-1655. 
Houser, Daniel, Stefan Vetter, and Joachim Winter, 2012, "Fairness and cheating." European Economic Review, 56 (8), 1645-1655.

Hunt, Jennifer, 2007, "How corruption hits people when they are down." Journal of Development Economics, 84 (2), $574-589$.

Jetter, Michael and Christopher F. Parmeter, 2018, "Sorting through global corruption determinants: institutions and education matter - not culture." World Development, 109, 279 - 294.

Kajackaite, Agne and Uri Gneezy, 2017, "Incentives and cheating." Games and Economic Behavior, 102, 433-444.

Kis-Katos, Krisztina and Günther G. Schulze, 2013, "Corruption in Southeast Asia: a survey of recent research." Asian-Pacific Economic Literature, 27 (1), 79-109.

Kuecken, Maria and Marie-Anne Valfort, 2019, "Information reduces corruption and improves enrolment (but not schooling): a replication study of a newspaper campaign in Uganda." The Journal of Development Studies, 55 (5), 1007-1029.

Lambsdorff, Johann Graf, The institutional economics of corruption and reform: theory, evidence and policy, Cambridge University Press, 2007.

Lehne, Jonathan, Jacob N. Shapiro, and Oliver Vanden Eynde, 2018, "Building connections: political corruption and road construction in India." Journal of Development Economics, 131, 62-78.

Lewbel, Arthur, 2012, "Using heteroscedasticity to identify and estimate mismeasured and endogenous regressor models." Journal of Business 83 Economic Statistics, 30 (1), 67-80.

Mann, Heather, Ximena Garcia-Rada, Lars Hornuf, Juan Tafurt, and Dan Ariely, 2016, "Cut from the same cloth: similarly dishonest individuals across countries." Journal of Cross-Cultural Psychology, 47 (6), 858-874.

Martinelli, César, Susan W. Parker, Ana Cristina Pérez-Gea, and Rodimiro Rodrigo, 2018, "Cheating and incentives: learning from a policy experiment." American Economic Journal: Economic Policy, 10 (1), 298-325.

Mauro, Paolo, 1995, "Corruption and growth." The Quarterly Journal of Economics, 110 (3), 681-712.

Olken, Benjamin A., 2009, "Corruption perceptions vs. corruption reality." Journal of Public Economics, 93 (7), 950-964. 
Olken, Benjamin A. and Rohini Pande, 2012, "Corruption in developing countries." Annual Review of Economics, 4 (1), 479-509.

Phongpaichit, Pasuk and Sangsit Phiriyarangsan, Corruption and Democracy in Thailand, Silkworm Books, 1996.

Rilke, Rainer Michael, Anastasia Danilov, Ori Weisel, Shaul Shalvi, and Bernd Irlenbusch, "When leading by example leads to less corrupt collaboration." 2019. Mimeo.

Sequeira, Sandra and Simeon Djankov, 2014, "Corruption and firm behavior: evidence from African ports." Journal of International Economics, 94 (2), 277 - 294.

Sulemana, Iddisah, Abdul Malik Iddrisu, and Jude E. Kyoore, 2017, "A micro-level study of the relationship between experienced corruption and subjective wellbeing in Africa." The Journal of Development Studies, 53 (1), 138-155.

Svensson, Jakob, 2005, "Eight questions about corruption." Journal of Economic Perspectives, 19 (3), $19-42$.

Vadlamannati, Krishna Chaitanya and Arusha Cooray, 2017, "Transparency pays? Evaluating the effects of the freedom of information laws on perceived government corruption." The Journal of Development Studies, 53 (1), 116-137.

World Bank, "Worldwide Governance Indicators 2018." www.govindicators.org 2018. Accessed: March 2020. 


\section{Tables and figures}

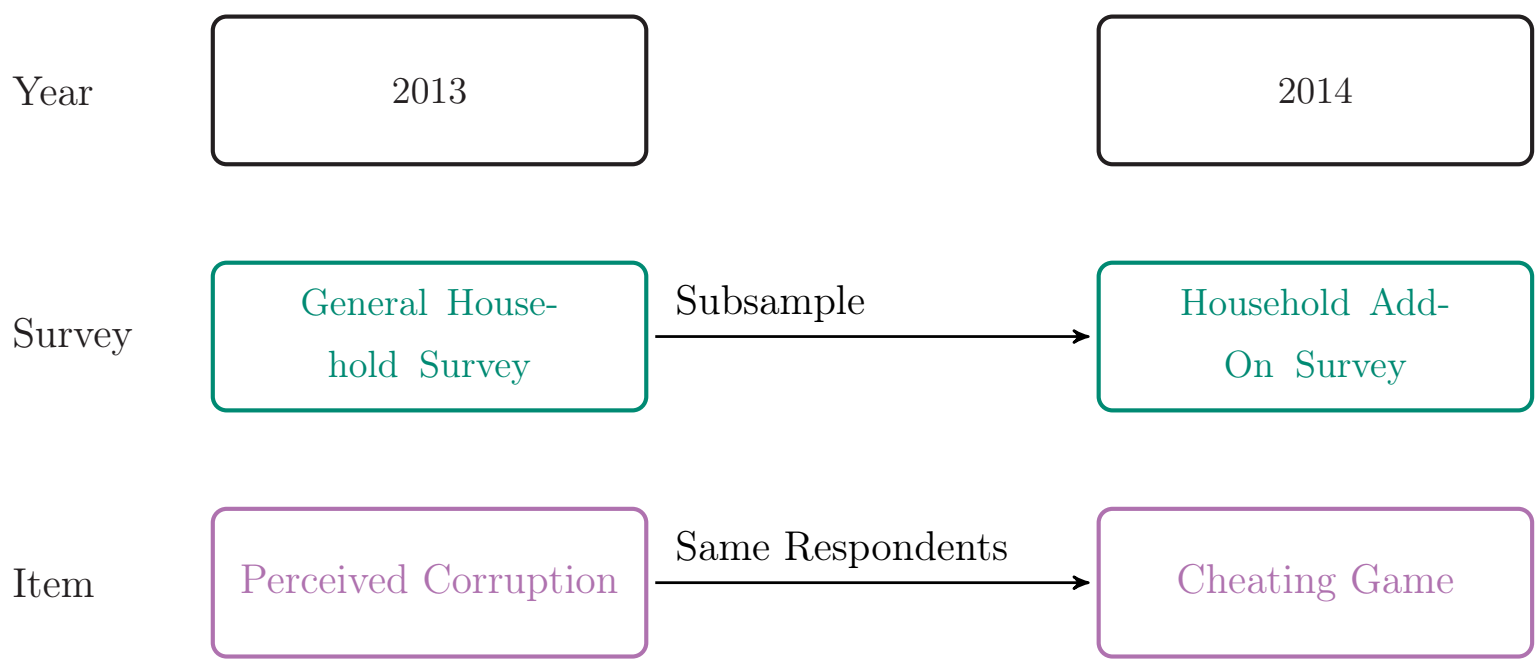

Figure 1: Timeline of the Study

Table 1: Descriptive Statistics

\begin{tabular}{lcccc}
\hline & Full Information & Only Experiment & Full Sample & $\begin{array}{c}\text { Difference } \\
\text { Only - Full Info }\end{array}$ \\
\hline Male & 0.35 & 0.40 & 0.37 & 0.06 \\
Age & 55.24 & 49.38 & 52.97 & $-5.86^{* * *}$ \\
Education & 5.47 & 6.64 & 5.92 & $1.17^{* * *}$ \\
Consumption per Cap. & 7.09 & 7.09 & 7.09 & -0.01 \\
Asset Value & 8.15 & 8.32 & 8.21 & 0.17 \\
Risk Taking, MPL & 10.96 & 11.08 & 10.99 & 0.12 \\
Confidence & 2.42 & 2.42 & 2.42 & 0.00 \\
Trust in Outsiders & 1.61 & 1.66 & 1.63 & 0.05 \\
Attendants & 1.40 & 1.57 & 1.47 & 0.17 \\
Attendants Dummy & 0.64 & 0.67 & 0.65 & 0.03 \\
\hline Observations & 523 & 335 & 860 & 858 \\
\hline
\end{tabular}

Variables: Male $(0=$ female; $1=$ male), Age(years), Education(years), Consumption per Cap.(annually, in log US-Dollar), Asset Value(log total value of all hh assets), Risk Taking, MPL(switching row from lottery to safe value, from 1 to 21), Confidence(in agricultural decisions from 1-always confident to 5never confident), Trust in Outsiders(1-trust them not at all to 5-trust them a lot), Attendants(no. of attendants), Attendants Dummy ( $0=$ no attendants; $1=$ attendants $)$, Perceived Corruption $(0=$ no; $1=$ yes $)$.

${ }^{*} \mathrm{p}<0.10,{ }^{* *} \mathrm{p}<0.05,{ }^{* * *} \mathrm{p}<0.01$ 
Figure 2: Distribution of Reported Rolled Numbers

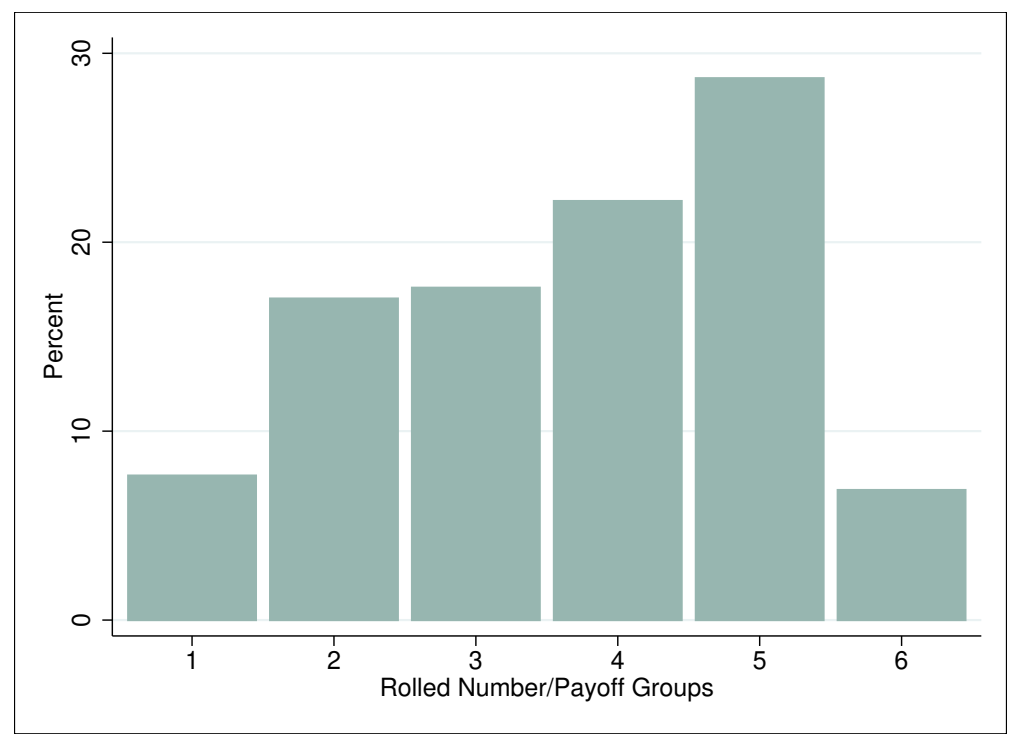

1: $7.65 \%, 2: 17.02 \%, 3: 17.59 \%, 4: 22.18 \%, 5: 28.68 \%, 6: 6.88 \%$.

Figure 3: Empirical Distributions of Standardized Cheating by Sex

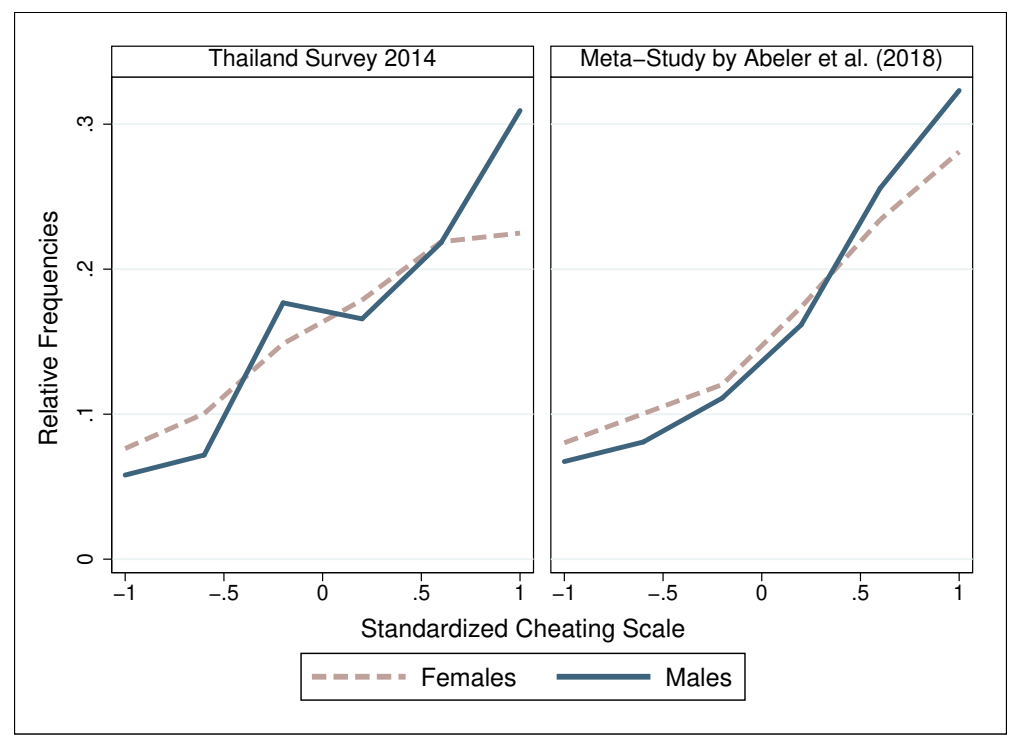

Note: Standardized scale from lowest to highest payoff. In the case of the left panel this implies from rolling a 6 to rolling a 5 . 
Figure 4: Perceived Corruption for Each Payoff Group

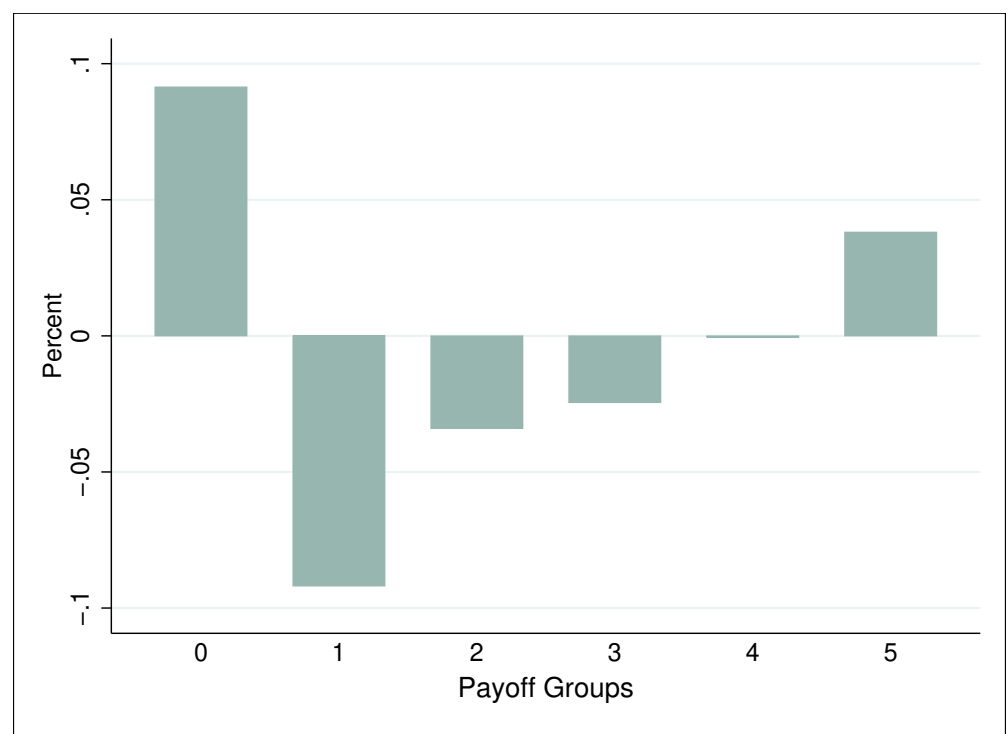

Note: Share of people who perceive corruption in each payoff group as deviation from the mean perceived corruption.

Table 2: Descriptive Statistics - Group who reported a 6 (0 payoff) vs. Others

\begin{tabular}{lcccc}
\hline & Full Information & Reported 6 & Others & Difference \\
\hline Male & 0.35 & 0.47 & 0.34 & $-0.14^{*}$ \\
Age & 55.24 & 52.28 & 55.46 & 3.18 \\
Education & 5.47 & 5.81 & 5.45 & -0.36 \\
Consumption per Cap. & 7.09 & 7.21 & 7.08 & -0.13 \\
Asset Value & 8.15 & 8.50 & 8.12 & -0.38 \\
Risk Taking, MPL & 10.96 & 9.75 & 11.05 & 1.30 \\
Confidence & 2.42 & 2.17 & 2.43 & 0.26 \\
Trust in Outsiders & 1.61 & 1.69 & 1.60 & -0.09 \\
Attendants & 1.40 & 1.42 & 1.40 & -0.01 \\
Attendants Dummy & 0.64 & 0.67 & 0.64 & -0.03 \\
Perceived Corruption & 0.74 & 0.83 & 0.74 & -0.10 \\
\hline Observations & 523 & 36 & 487 & 523 \\
\hline
\end{tabular}

Variables: $\operatorname{Male}(0=$ female; $1=$ male), Age(years), Education(years), Consumption per Cap.(annually, in $\log$ US-Dollar), Asset Value(log total value of all hh assets), Risk Taking, MPL(switching row from lottery to safe value, from 1 to 21), Confidence(in agricultural decisions from 1-always confident to 5never confident), Trust in Outsiders(1-trust them not at all to 5-trust them a lot), Attendants(no. of attendants), Attendants $\operatorname{Dummy}(0=$ no attendants; $1=$ attendants $)$, Perceived Corruption $(0=$ no; $1=$ yes $)$. ${ }^{*} \mathrm{p}<0.10,{ }^{* *} \mathrm{p}<0.05, * * * \mathrm{p}<0.01$ 
Figure 5: Number of Attendants

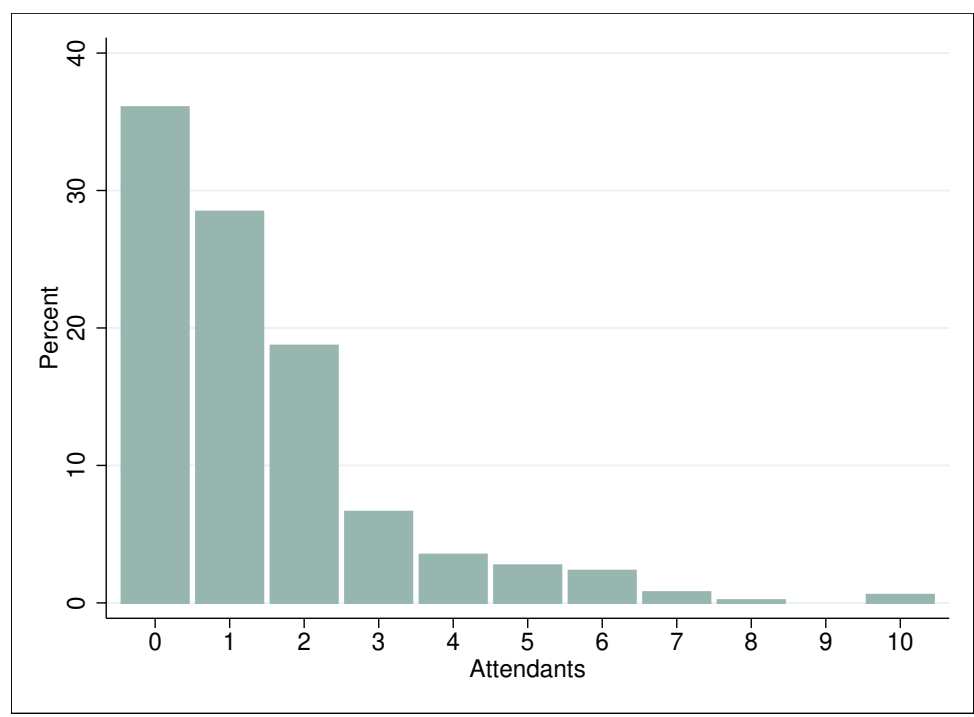


Table 3: Regression Estimates with Weights and Lewbel Estimation

\begin{tabular}{|c|c|c|c|c|c|}
\hline & (1) & (2) & (3) & (4) & (IV) \\
\hline Perceived Corruption & $\begin{array}{l}0.330^{* *} \\
(0.146)\end{array}$ & $\begin{array}{c}0.266^{*} \\
(0.146)\end{array}$ & $\begin{array}{l}0.295^{* *} \\
(0.144)\end{array}$ & $\begin{array}{c}0.348^{* *} \\
(0.144)\end{array}$ & $\begin{array}{c}2.004^{* *} \\
(0.918)\end{array}$ \\
\hline Male & $\begin{array}{c}0.031 \\
(0.147)\end{array}$ & $\begin{array}{c}0.065 \\
(0.146)\end{array}$ & $\begin{array}{c}0.011 \\
(0.147)\end{array}$ & & $\begin{array}{c}-0.036 \\
(0.169)\end{array}$ \\
\hline Age & $\begin{array}{c}-0.081^{* *} \\
(0.039)\end{array}$ & $\begin{array}{c}-0.070^{*} \\
(0.038)\end{array}$ & $\begin{array}{c}-0.086^{* *} \\
(0.039)\end{array}$ & $\begin{array}{c}-0.074^{* *} \\
(0.036)\end{array}$ & $\begin{array}{c}-0.086^{* *} \\
(0.043)\end{array}$ \\
\hline $\mathrm{Age}^{2}$ & $\begin{array}{c}0.001^{* *} \\
(0.000)\end{array}$ & $\begin{array}{c}0.001^{* *} \\
(0.000)\end{array}$ & $\begin{array}{l}0.001^{* *} \\
(0.000)\end{array}$ & $\begin{array}{l}0.001^{* *} \\
(0.000)\end{array}$ & $\begin{array}{l}0.001^{* *} \\
(0.000)\end{array}$ \\
\hline Education & $\begin{array}{c}0.014 \\
(0.026)\end{array}$ & $\begin{array}{c}0.030 \\
(0.025)\end{array}$ & $\begin{array}{c}0.015 \\
(0.026)\end{array}$ & & $\begin{array}{c}-0.009 \\
(0.032)\end{array}$ \\
\hline Consumption per Cap. & $\begin{array}{c}0.038 \\
(0.120)\end{array}$ & & $\begin{array}{c}0.039 \\
(0.120)\end{array}$ & & $\begin{array}{c}0.014 \\
(0.135)\end{array}$ \\
\hline Risk Taking, MPL & $\begin{array}{c}0.013 \\
(0.009)\end{array}$ & $\begin{array}{c}0.014 \\
(0.008)\end{array}$ & $\begin{array}{c}0.012 \\
(0.009)\end{array}$ & & $\begin{array}{c}0.015 \\
(0.010)\end{array}$ \\
\hline Confidence & $\begin{array}{c}0.039 \\
(0.067)\end{array}$ & $\begin{array}{c}0.058 \\
(0.067)\end{array}$ & $\begin{array}{c}0.034 \\
(0.067)\end{array}$ & & $\begin{array}{c}0.001 \\
(0.078)\end{array}$ \\
\hline Trust in Outsiders & $\begin{array}{c}-0.128 \\
(0.085)\end{array}$ & $\begin{array}{c}-0.135 \\
(0.084)\end{array}$ & $\begin{array}{c}-0.120 \\
(0.085)\end{array}$ & & $\begin{array}{c}-0.134 \\
(0.095)\end{array}$ \\
\hline Attendants & $\begin{array}{c}-0.096^{* *} \\
(0.041)\end{array}$ & $\begin{array}{c}-0.104^{* * *} \\
(0.040)\end{array}$ & & $\begin{array}{c}-0.113^{* * *} \\
(0.039)\end{array}$ & $\begin{array}{c}-0.170^{* * * *} \\
(0.061)\end{array}$ \\
\hline Asset Value & & $\begin{array}{c}-0.083^{*} \\
(0.049)\end{array}$ & & $\begin{array}{c}-0.057 \\
(0.047)\end{array}$ & \\
\hline Attendants Dummy & & & $\begin{array}{c}-0.344^{* *} \\
(0.144)\end{array}$ & & \\
\hline Constant & $\begin{array}{l}3.854^{* * *} \\
(1.263)\end{array}$ & $\begin{array}{l}4.477^{* * *} \\
(1.140)\end{array}$ & $\begin{array}{l}4.095^{* * *} \\
(1.273)\end{array}$ & $\begin{array}{l}4.700^{* * *} \\
(1.060)\end{array}$ & $\begin{array}{l}3.268^{* *} \\
(1.450)\end{array}$ \\
\hline Observations & 471 & 471 & 471 & 474 & 471 \\
\hline Adj. R-Squared & 0.026 & 0.036 & 0.027 & 0.027 & \\
\hline
\end{tabular}

Indep. Variables: Perceived Corruption $(0=$ no; $1=$ yes $)$, Male $(0=$ female; $1=$ male $)$, Age(years $)$, Education(years), Consumption per Cap.(annually, in log US-Dollar), Asset Value(log total value of all hh assets), Risk Taking, MPL(switching row from lottery to safe value, from 1 to 21), Confidence(in agricultural decisions from 1-always confident to 5 -never confident), Trust in Outsiders(1-trust them not at all to 5 -trust them a lot), Attendants(no. of attendants), Attendants Dummy ( $0=$ no attendants; $1=$ attendants $)$. S.E. in parentheses.

${ }^{*} \mathrm{p}<0.10,{ }^{* *} \mathrm{p}<0.05,{ }^{* * *} \mathrm{p}<0.01$ 


\section{Appendix}

\section{A Instructions}

1 Which number is rolled by the die? (Please show the payoff table to the respondent and pass him the box and the six-sided die.
Ask him to secretly roll the die several times and to keep the first number he rolled in mind.)

\begin{tabular}{|l|l|}
\hline Number rolled & Payoff \\
\hline 1 & 50 \\
\hline 2 & 100 \\
\hline 3 & 150 \\
\hline 4 & 200 \\
\hline 5 & 250 \\
\hline 6 & 0 \\
\hline
\end{tabular}

2 What is the first number rolled? Rolled number $\square$

3 How many persons are currently around and watching the scenario? (Do not count the respondent and the enumerator)

\section{B Individual attitudes and characteristics}

Evidence on the relationships between cheating and covarying characteristics is quite thin. This is surprising as there appear to be many plausible relations between several of these characteristics and cheating. A reason for the lack of evidence could be the fact that most experiments are conducted in the lab with students, meaning that there is not much variation between subjects. In the following, we discuss the hypotheses based on socio-demographic characteristics in more detail.

(i) Our first hypothesis is that men will cheat more than women, because this relation is generally found (e.g. Houser et al., 2012) and also found with respect to the specific experiment applied here (Abeler et al., 2019).

(ii) Following the metastudy of Abeler et al. (2019), we expect a slightly negative relation between cheating and age.

(iii) A kind of ambiguous relation may apply to education, as, on the hand, the better educated are expected to be more aware that cheating is a norm violation, but on the other hand, they may also better realize the economic advantage of cheating.

(iv) The relation of cheating to consumption (or income) is potentially ambiguous as well. Individuals with higher consumption level have a lower financial incentive to cheat. 
At the same time, Abeler et al. (2014) argue that there may be reverse causality in the sense that individuals have realized higher consumption because they are less concerned about cheating. Boonmanunt et al. (2020) do not find an effect for income in a sample very similar to ours. Alternatively, we look at wealth, which might be less volatile than income from harvest and measures the underlying affluence of a household. To measure wealth, we take the $(\log )$ value of all larger assets households report to own. These assets include typically household appliances, agricultural equipment, and vehicles.

Figure B.1: Multiple Price List for Risk Taking

1 Do you prefer to play the 50:50-lottery(Option A) or to obtain a safe amount (Option B)? (Please show the show card to the respondent and ask him row by row which option he prefers. Tick the appropriate cell that corresponds to respondent's choice.

\begin{tabular}{|l|l|l|l|l|}
\hline \multirow{2}{*}{ Row } & $\begin{array}{l}\text { Option A } \\
\text { Lottery }\end{array}$ & $\begin{array}{l}\text { Option B } \\
\text { Safe Amount }\end{array}$ & \multicolumn{2}{|l|}{ Choice: } \\
\hline & THB & THB & A & B \\
\hline 1 & $300: 0$ & 0 & & \\
\hline 2 & $300: 0$ & 10 & & \\
\hline 3 & $300: 0$ & 20 & & \\
\hline 4 & $300: 0$ & 30 & & \\
\hline 5 & $300: 0$ & 40 & & \\
\hline 6 & $300: 0$ & 50 & & \\
\hline 7 & $300: 0$ & 60 & & \\
\hline 8 & $300: 0$ & 70 & & \\
\hline 9 & $300: 0$ & 80 & & \\
\hline 10 & $300: 0$ & 90 & & \\
\hline 11 & $300: 0$ & 100 & & \\
\hline 12 & $300: 0$ & 110 & & \\
\hline 13 & $300: 0$ & 120 & & \\
\hline 14 & $300: 0$ & 130 & & \\
\hline 15 & $300: 0$ & 140 & & \\
\hline 16 & $300: 0$ & 150 & & \\
\hline 17 & $300: 0$ & 160 & & \\
\hline 18 & $300: 0$ & 170 & & \\
\hline 19 & $300: 0$ & 180 & & \\
\hline 20 & $300: 0$ & 190 & & \\
\hline
\end{tabular}


Figure B.2: Distribution of Switching Rows in MPL for Risk Taking

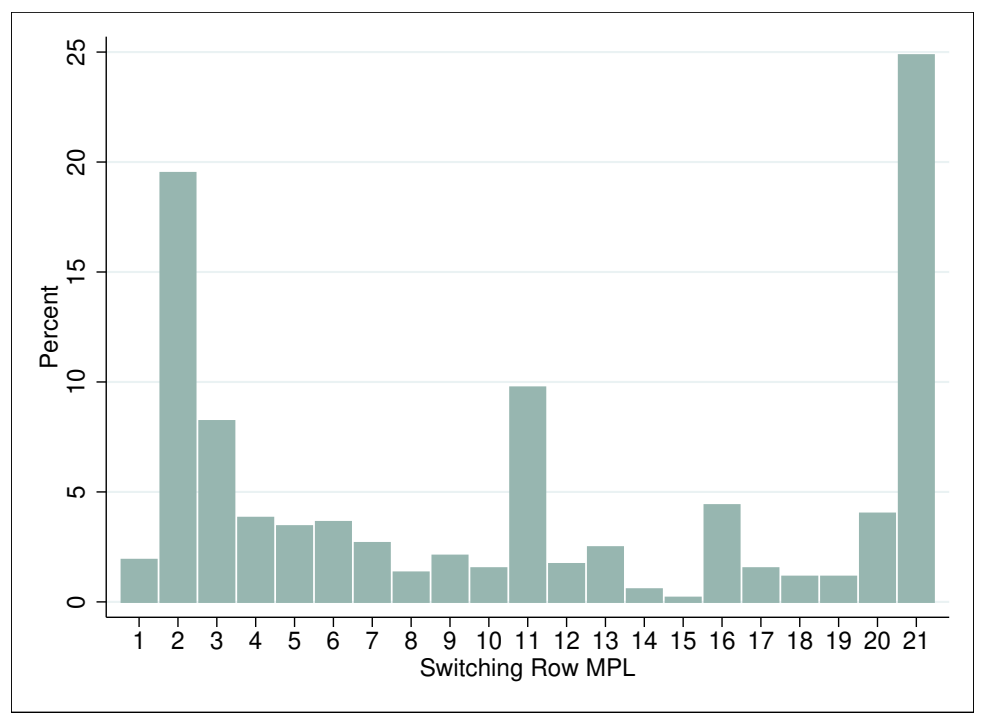

Figure B.3: Distribution of Confidence in Agricultural Decisions

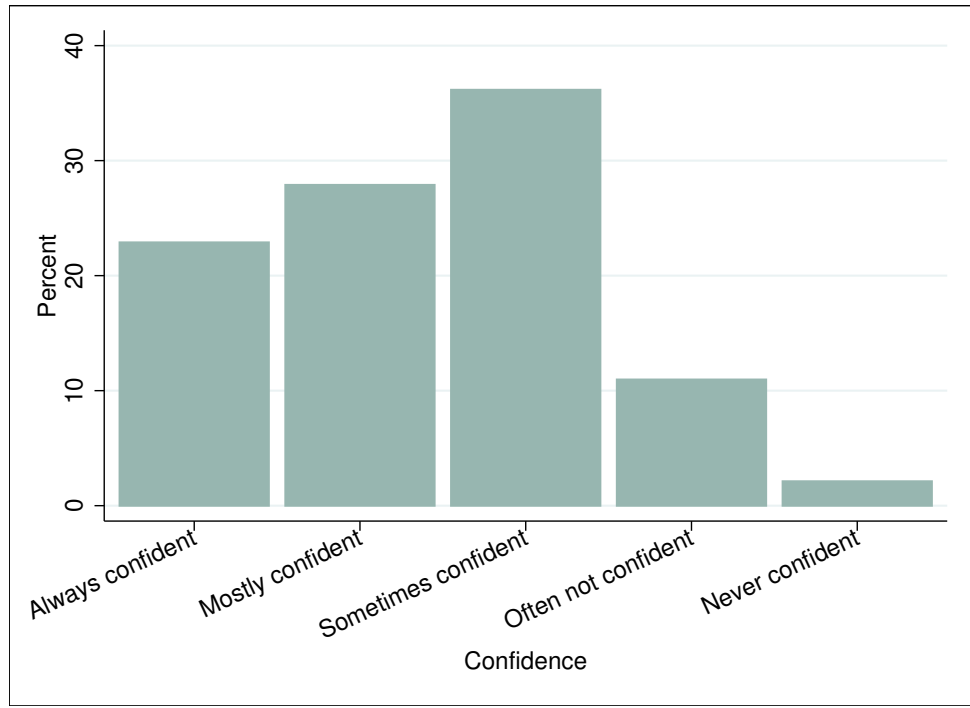


Figure B.4: Distribution of Trust in Outsiders

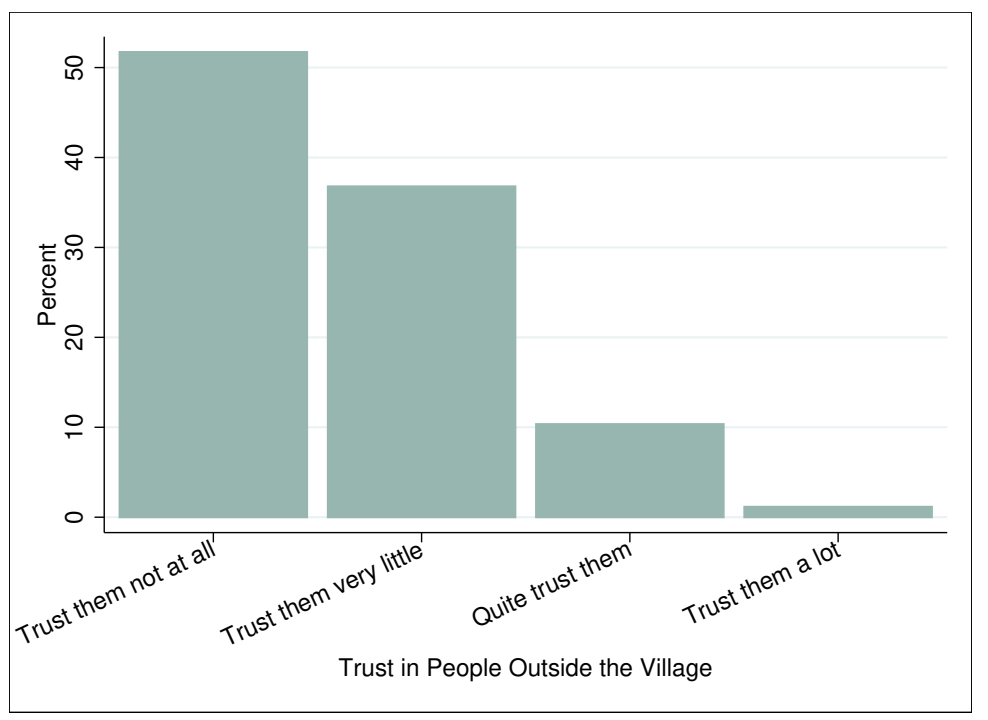

\section{Implementation of the weighted OLS approach}

Weighting schemes should be based on the basic population but this information is not available. Therefore, conducted estimates are weighted by the observed frequencies in each category under the maximum available sample size. Furthermore, the weights are standardized by the share of persons who reported to have rolled a 6 . The observed frequency distribution implies that the weighting is based on the full sample of participating individuals, i.e. 860 persons, while our benchmark regression (in Table 3, column 1) is based on 510 observations. There are two reasons to use the large sample: first, the largest possible sample provides the best information approximating the true full sample. Second, if we use a reduced sample, weights had to be calculated several times due to the different sample sizes, which would induce an element of variation that makes the results less comparable.

We recode the stated numbers into an ordered variable with respect to the outcome (Table C.2). The purpose is to receive a uniformly ordered variable. The weights are then determined in four steps.

- Step 1: We calculate the number of observations under the assumption of a uniform distribution, this means in our sample 860/6 = 143(.333).

- Step 2: We calculate the difference between the actual number of observations and the number of observations under step $1: 0: 59-143=-84 ; 1: 76-143=-67 ; 2: 138$ $143=-5 ; 3: 149-143=6 ; 4: 188-143=45 ; 5: 250-143=107$. This actual number of 
observations minus the theoretical number under a uniform distribution is a hint of the degree of cheating. The greater the difference the higher is the probability that the respondent lies.

- Step 3: We determine the difference between the results of step 2 minus the result of step 2 for 0 . This means: $0:-84+84=0 ; 1:-67+84=17 ; 2:-5+84=79 ; 3: 6+84=90$; 4: $45+84=129 ; 5: 107+84=191)$.

- Step 4: The reciprocal values of step 3 are the elements of a grouping matrix (Johnston 1972, p. 228):
1: $1 / 17=0.0588235$
2: $1 / 79=0.0126582$
3: $1 / 90=0.0111111$
4: $1 / 129=0.0077519$
5: $1 / 191=0.0052356$

The expression for 0 is indeterminate $(1 / 0)$. Therefore, one has to assume a small number different from zero, namely $1 / 10000$. We would like to emphasize, however, that we exclude this group (those with a payoff of 0 ) from all our main regressions, so that the number chosen does not matter.

Using these weights, estimates of a standard model of cheating are presented in Table 3. We use this weighting scheme for all estimates.

Table C.1: Frequency Distribution of Rolled Number

\begin{tabular}{cccc}
\hline Dice & Frequency & Percent & Cumulative \\
\hline 1 & 76 & 8.84 & 8.84 \\
2 & 138 & 16.05 & 24.88 \\
3 & 149 & 17.33 & 42.21 \\
4 & 188 & 21.86 & 64.07 \\
5 & 250 & 29.07 & 93.14 \\
6 & 59 & 6.86 & 100.00 \\
\hline Total & 860 & 100.00 & \\
\hline
\end{tabular}


Table C.2: Recoded Frequency Distribution

\begin{tabular}{cccc}
\hline Pay & Frequency & Percent & Cumulative \\
\hline 0 & 59 & 6.86 & 100.00 \\
1 & 76 & 8.84 & 8.84 \\
2 & 138 & 16.05 & 24.88 \\
3 & 149 & 17.33 & 42.21 \\
4 & 188 & 21.86 & 64.07 \\
5 & 250 & 29.07 & 93.14 \\
\hline Total & 860 & 100.00 & \\
\hline
\end{tabular}

\section{Robustness tables}

In this Appendix documenting robustness checks, we address four issues. First, different empirical models are applied, confirming that weighted estimates not including those who report a 6 are superior to alternatives (Subsection D.1). Second, we analyze cheating behavior by defining different forms of cheating behavior, i.e. we modify the LHS-variable (Subsection D.2). Third, we define perceived corruption differently, i.e. we modify the RHS-variable (Subsection D.3). Fourth, we split the sample regarding whether there were attendants at the cheating experiment or not (Subsection D.4).

\section{D.1 Alternative empirical models}

While the presented weighted linear regression model seems to be justified from an $e x$ ante perspective, here we show that alternative empirical models provide largely the same information. This may be reassuring, however, the alternatives obviously deliver less significant coefficients. In Table D.1, we present the results for four such models. In column (1), we also use a weighted OLS, however, here we only correct for the deviations from the theoretical population distribution, such that the five groups receive the same weight in the regression. The weights here are roughly 3 to 1 from group 1 to group 5, while the span of weight is 10 to 1 in our main specification. In column (2), we use an interval regression (assuming that the cheating variable is a continuous variable within classes), in column (3) an ordered logit regression (in order to take account of the ordered nature of the experimental outcome variable), and in column (4) a standard OLS-regression.

The estimates demonstrate that the preferred weighted regression approach is superior to the alternatives shown here, regarding its explanatory power. In the first three columns, the corruption variable remains marginally significant while most other coefficients are insignificant. As expected, the standard OLS has even less explanatory power. 
Table D.1: Sample Weights, Interval, Ordered Logit and OLS Regressions

\begin{tabular}{|c|c|c|c|c|}
\hline & Sample Weights & Interval & O. Logit & OLS \\
\hline \multirow[t]{2}{*}{ Perceived Corruption } & $0.261^{*}$ & $14.489 *$ & $0.326^{*}$ & $0.229^{*}$ \\
\hline & $(0.143)$ & $(8.392)$ & $(0.189)$ & $(0.138)$ \\
\hline \multirow[t]{2}{*}{ Male } & 0.040 & -0.996 & -0.015 & 0.009 \\
\hline & $(0.141)$ & $(8.222)$ & $(0.184)$ & $(0.135)$ \\
\hline \multirow[t]{2}{*}{ Age } & $-0.059^{*}$ & $-3.864^{*}$ & $-0.089^{*}$ & $-0.054^{*}$ \\
\hline & $(0.035)$ & $(1.997)$ & $(0.046)$ & $(0.032)$ \\
\hline \multirow[t]{2}{*}{$\mathrm{Age}^{2}$} & $0.001^{*}$ & $0.037^{* *}$ & $0.001^{* *}$ & $0.001^{*}$ \\
\hline & $(0.000)$ & $(0.018)$ & $(0.000)$ & $(0.000)$ \\
\hline \multirow[t]{2}{*}{ Education } & 0.002 & -0.738 & -0.017 & -0.009 \\
\hline & $(0.024)$ & $(1.411)$ & $(0.031)$ & $(0.023)$ \\
\hline \multirow[t]{2}{*}{ Consumption per Cap. } & 0.041 & 3.482 & 0.087 & 0.047 \\
\hline & $(0.114)$ & (6.653) & $(0.149)$ & (0.109) \\
\hline \multirow[t]{2}{*}{ Risk Taking, MPL } & 0.007 & -0.118 & -0.004 & -0.000 \\
\hline & $(0.008)$ & $(0.492)$ & $(0.011)$ & $(0.008)$ \\
\hline \multirow[t]{2}{*}{ Confidence } & 0.065 & 3.646 & 0.086 & 0.066 \\
\hline & $(0.064)$ & $(3.716)$ & $(0.083)$ & $(0.061)$ \\
\hline \multirow[t]{2}{*}{ Trust in Outsiders } & -0.079 & 1.402 & 0.034 & -0.006 \\
\hline & $(0.087)$ & $(5.194)$ & $(0.119)$ & $(0.085)$ \\
\hline \multirow[t]{2}{*}{ Attendants } & $-0.069^{*}$ & -2.797 & -0.058 & -0.047 \\
\hline & $(0.038)$ & $(2.214)$ & $(0.049)$ & $(0.036)$ \\
\hline \multirow[t]{2}{*}{ Constant } & $3.939 * * *$ & $267.196^{* * *}$ & & $4.309^{* * *}$ \\
\hline & $(1.191)$ & $(69.283)$ & & $(1.132)$ \\
\hline \multirow[t]{2}{*}{ lnsigma } & & $4.325^{* * *}$ & & \\
\hline & & $(0.043)$ & & \\
\hline \multirow[t]{2}{*}{ cut1 } & & & $-3.777^{* *}$ & \\
\hline & & & $(1.562)$ & \\
\hline \multirow[t]{2}{*}{ cut2 } & & & -2.353 & \\
\hline & & & $(1.557)$ & \\
\hline \multirow[t]{2}{*}{ cut3 } & & & -1.510 & \\
\hline & & & $(1.555)$ & \\
\hline \multirow[t]{2}{*}{ cut4 } & & & -0.477 & \\
\hline & & & $(1.553)$ & \\
\hline Observations & 471 & 471 & 471 & 471 \\
\hline
\end{tabular}

Indep. Variables: Perceived Corruption $(0=$ no; $1=$ yes $)$, Male $(0=$ female; $1=$ male $)$, Age(years $)$, Education(years), Consumption per Cap.(annually, in log US-Dollar), Risk Taking, MPL(switching row from lottery to safe value, from 1 to 21), Confidence(in agricultural decisions from 1-always confident to 5never confident), Trust in Outsiders(1-trust them not at all to 5-trust them a lot), Attendants(no. of attendants). S.E. in parentheses.

$* \mathrm{p}<0.10,{ }^{* *} \mathrm{p}<0.05,{ }^{* * *} \mathrm{p}<0.01$ 
Furthermore, Table D.2 shows that, as expected, an OLS regression including all observations does not reveal a significant effect of corruption on cheating.

Table D.2: OLS Regressions Including Zero Payoff Group

\begin{tabular}{|c|c|c|c|}
\hline & (1) & (2) & (3) \\
\hline Perceived Corruption & $\begin{array}{c}0.130 \\
(0.159)\end{array}$ & $\begin{array}{c}0.112 \\
(0.158)\end{array}$ & $\begin{array}{c}0.119 \\
(0.159)\end{array}$ \\
\hline Male & $\begin{array}{c}-0.131 \\
(0.153)\end{array}$ & $\begin{array}{c}-0.116 \\
(0.152)\end{array}$ & $\begin{array}{c}-0.137 \\
(0.153)\end{array}$ \\
\hline Age & $\begin{array}{c}-0.061^{*} \\
(0.036)\end{array}$ & $\begin{array}{c}-0.060^{*} \\
(0.036)\end{array}$ & $\begin{array}{c}-0.061^{*} \\
(0.037)\end{array}$ \\
\hline $\mathrm{Age}^{2}$ & $\begin{array}{c}0.001^{*} \\
(0.000)\end{array}$ & $\begin{array}{c}0.001^{*} \\
(0.000)\end{array}$ & $\begin{array}{c}0.001^{*} \\
(0.000)\end{array}$ \\
\hline Education & $\begin{array}{c}-0.007 \\
(0.026)\end{array}$ & $\begin{array}{c}-0.006 \\
(0.025)\end{array}$ & $\begin{array}{c}-0.007 \\
(0.026)\end{array}$ \\
\hline Consumption per Cap. & $\begin{array}{c}-0.018 \\
(0.123)\end{array}$ & & $\begin{array}{c}-0.022 \\
(0.123)\end{array}$ \\
\hline Risk Taking, MPL & $\begin{array}{c}0.006 \\
(0.009)\end{array}$ & $\begin{array}{c}0.007 \\
(0.009)\end{array}$ & $\begin{array}{c}0.006 \\
(0.009)\end{array}$ \\
\hline Confidence & $\begin{array}{c}0.106 \\
(0.069)\end{array}$ & $\begin{array}{c}0.109 \\
(0.069)\end{array}$ & $\begin{array}{c}0.101 \\
(0.069)\end{array}$ \\
\hline Trust in Outsiders & $\begin{array}{c}-0.053 \\
(0.097)\end{array}$ & $\begin{array}{c}-0.055 \\
(0.097)\end{array}$ & $\begin{array}{c}-0.051 \\
(0.097)\end{array}$ \\
\hline Attendants & $\begin{array}{c}-0.055 \\
(0.042)\end{array}$ & $\begin{array}{c}-0.059 \\
(0.041)\end{array}$ & \\
\hline Asset Value & & $\begin{array}{c}-0.025 \\
(0.051)\end{array}$ & \\
\hline Attendants Dummy & & & $\begin{array}{c}-0.134 \\
(0.145)\end{array}$ \\
\hline Constant & $\begin{array}{l}4.562^{* * *} \\
(1.286)\end{array}$ & $\begin{array}{l}4.627^{* * *} \\
(1.139)\end{array}$ & $\begin{array}{l}4.620^{* * *} \\
(1.293)\end{array}$ \\
\hline Observations & 506 & 506 & 506 \\
\hline Adj. R-Squared & 0.004 & 0.005 & 0.002 \\
\hline
\end{tabular}

Indep. Variables: Perceived Corruption $(0=$ no; $1=$ yes $)$, Male $(0=$ female; $1=$ male $)$, Age(years), Education(years), Consumption per Cap.(annually, in log US-Dollar), Asset Value(log total value of all hh assets), Risk Taking, MPL(switching row from lottery to safe value, from 1 to 21), Confidence(in agricultural decisions from 1-always confident to 5 -never confident), Trust in Outsiders(1-trust them not at all to 5 -trust them a lot), Attendants(no. of attendants), Attendants Dummy ( $0=$ no attendants; $1=$ attendants $)$. S.E. in parentheses.

${ }^{*} \mathrm{p}<0.10,{ }^{* *} \mathrm{p}<0.05,{ }^{* * *} \mathrm{p}<0.01$ 


\section{D.2 Results for different definitions of the cheating variable}

In this part, we test the robustness of our main findings with respect to variations of the underlying endogenous variable. We aggregate cheating categories to dummies in order to clarify the empirical concept of cheating and assume that individuals reporting higher outcomes are more likely to have cheated. For example, we form a dummy, pay $45=1$, if people have a reported outcome of 4 or 5 , while all other outcomes are set to zero. The hypothesis is that people in pay $45=1$ have a higher lying potential and, thus, the lying effects might be clearer than in Table 3. However, the result shown in Table D.3, column (1), does not reveal any new relations.

Of course, we do not know who is truly cheating and, thus, we cannot know the best cut-off to distinguish between a high and a low probability of cheating. Therefore, we apply different cut-offs. Besides pay45, we merge the outcomes of 3, 4 and 5 into another cheating category. Finally, 2 to 5 are combined. We test whether pay45, pay345, or pay2345 allows the best modelling of cheating. Looking at the results in Table D.3, we do not discover fundamental differences. The signs are always the same for all variables. The degree of significance is larger for pay345 and pay2345 compared to pay45. Therefore, these results confirm our main findings in Table 3. 
Table D.3: Weighted Regression Estimates for Aggregated Cheating Variables

\begin{tabular}{lccc}
\hline & pay45 & pay345 & pay2345 \\
\hline Perceived Corruption & $0.081^{*}$ & $0.087^{*}$ & $0.107^{* *}$ \\
Male & $(0.046)$ & $(0.051)$ & $(0.049)$ \\
& 0.017 & 0.033 & 0.003 \\
Age & $(0.046)$ & $(0.051)$ & $(0.049)$ \\
& -0.017 & -0.018 & $-0.024^{*}$ \\
Age & & $(0.013)$ & $(0.013)$ \\
& $(0.012)$ & 0.000 & $0.000^{* *}$ \\
Education & 0.000 & $(0.000)$ & $(0.000)$ \\
& $(0.000)$ & 0.005 & 0.013 \\
Consumption per Cap. & -0.002 & $(0.009)$ & $(0.009)$ \\
& $(0.008)$ & 0.022 & 0.006 \\
Risk Taking, MPL & -0.004 & $(0.042)$ & $(0.040)$ \\
& $(0.038)$ & $0.007^{* *}$ & $0.006^{* *}$ \\
Confidence & 0.001 & $(0.003)$ & $(0.003)$ \\
Trust in Outsiders & $(0.003)$ & 0.022 & -0.012 \\
& 0.026 & $(0.023)$ & $(0.022)$ \\
Attendants & $(0.021)$ & -0.037 & $-0.062^{* *}$ \\
Constant & -0.043 & $(0.030)$ & $(0.028)$ \\
& $(0.027)$ & -0.023 & $-0.034^{* *}$ \\
\hline Observations & $-0.026^{* *}$ & $(0.014)$ & $(0.014)$ \\
Adj. R-Squared & $(0.013)$ & 0.572 & $1.041^{* *}$ \\
\hline
\end{tabular}

Dependent variables: pay 45 equals 1 if 4 or 5 are reported as rolled number and 0 otherwise, pay345 and pay2345 are analogously defined.

Indep. Variables: Perceived Corruption $(0=$ no; $1=$ yes $)$, Male $(0=$ female; $1=$ male $)$, Age(years $)$, Education(years), Consumption per Cap.(annually, in log US-Dollar), Risk Taking, MPL(switching row from lottery to safe value, from 1 to 21), Confidence(in agricultural decisions from 1-always confident to 5never confident), Trust in Outsiders(1-trust them not at all to 5 -trust them a lot), Attendants(no. of attendants). S.E. in parentheses.

$* \mathrm{p}<0.10,{ }^{* *} \mathrm{p}<0.05,{ }^{* * *} \mathrm{p}<0.01$

\section{D.3 Results for different definitions of the corruption variable}

Next, we vary the definition of our exogenous variable. In column (1) of Table D.4, we define our corruption variable to be zero, if corruption is never mentioned as main reason, to be one, if corruption is one of the two reasons, and to be two if corruption is stated two times (which a considerable amount of participants did). 
Table D.4: Weighted Regression Estimates for Different Corruption Variables

\begin{tabular}{|c|c|c|c|}
\hline & Double & Step 1 & Step 2 \\
\hline Corruption Double & $\begin{array}{l}0.378^{* * *} \\
(0.138)\end{array}$ & & \\
\hline Corruption Stepwise 1 & & $\begin{array}{l}0.326^{* * *} \\
(0.098)\end{array}$ & \\
\hline Corruption Stepwise 2 & & & $\begin{array}{c}0.145^{*} \\
(0.075)\end{array}$ \\
\hline Male & $\begin{array}{c}0.024 \\
(0.147)\end{array}$ & $\begin{array}{c}0.053 \\
(0.146)\end{array}$ & $\begin{array}{c}0.032 \\
(0.147)\end{array}$ \\
\hline Age & $\begin{array}{c}-0.081^{* *} \\
(0.038)\end{array}$ & $\begin{array}{c}-0.086^{* *} \\
(0.038)\end{array}$ & $\begin{array}{c}-0.080^{* *} \\
(0.039)\end{array}$ \\
\hline $\mathrm{Age}^{2}$ & $\begin{array}{l}0.001^{* *} \\
(0.000)\end{array}$ & $\begin{array}{c}0.001^{* *} \\
(0.000)\end{array}$ & $\begin{array}{c}0.001^{* *} \\
(0.000)\end{array}$ \\
\hline Education & $\begin{array}{c}0.015 \\
(0.026)\end{array}$ & $\begin{array}{c}0.011 \\
(0.026)\end{array}$ & $\begin{array}{c}0.017 \\
(0.026)\end{array}$ \\
\hline Consumption per Cap. & $\begin{array}{c}0.034 \\
(0.119)\end{array}$ & $\begin{array}{c}0.032 \\
(0.119)\end{array}$ & $\begin{array}{c}0.037 \\
(0.120)\end{array}$ \\
\hline Risk Taking, MPL & $\begin{array}{c}0.013 \\
(0.009)\end{array}$ & $\begin{array}{c}0.014 \\
(0.009)\end{array}$ & $\begin{array}{c}0.013 \\
(0.009)\end{array}$ \\
\hline Confidence & $\begin{array}{c}0.038 \\
(0.067)\end{array}$ & $\begin{array}{c}0.027 \\
(0.067)\end{array}$ & $\begin{array}{c}0.042 \\
(0.067)\end{array}$ \\
\hline Trust in Outsiders & $\begin{array}{c}-0.130 \\
(0.085)\end{array}$ & $\begin{array}{c}-0.130 \\
(0.085)\end{array}$ & $\begin{array}{c}-0.129 \\
(0.085)\end{array}$ \\
\hline Attendants & $\begin{array}{c}-0.098^{* *} \\
(0.041)\end{array}$ & $\begin{array}{c}-0.100^{* *} \\
(0.040)\end{array}$ & $\begin{array}{c}-0.095^{* *} \\
(0.041)\end{array}$ \\
\hline Constant & $\begin{array}{l}3.837^{* * *} \\
(1.260)\end{array}$ & $\begin{array}{l}3.747^{* * *} \\
(1.256)\end{array}$ & $\begin{array}{l}3.882^{\text {*** }} \\
(1.265)\end{array}$ \\
\hline Observations & 471 & 471 & 471 \\
\hline Adj. R-Squared & 0.031 & 0.039 & 0.023 \\
\hline
\end{tabular}

Independent Variables: Male $(0=$ female; $1=$ male), Age(years), Education(years), Consumption per Cap.(annually, in log US-Dollar), Risk Taking, MPL(switching row from lottery to safe value, from 1 to 21), Confidence(in agricultural decisions from 1-always confident to 5-never confident), Trust in Outsiders(1-trust them not at all to 5 -trust them a lot), Attendants(no. of attendants). S.E. in parentheses.

${ }^{*} \mathrm{p}<0.10,{ }^{* *} \mathrm{p}<0.05,{ }^{* * *} \mathrm{p}<0.01$

In column (2), the corruption variable ranges from 0 to 3 depending on if a reason besides corruption is stated or not (0-no corruption at all, 1-corruption and don't know, 2corruption and any of the other two reasons, 3-corruption stated twice). Column (3) orders the variable depending on how much the other answer categories indicate corruption as well (0-no corruption at all, 1-corruption and don't know or government offices inefficient, 
2-corruption and government procedures expensive, 3-corruption stated twice). These re-definitions do not reveal further insights.

\section{D.4 Considering attendance vs. no attendance}

We consider the case of attendants watching the experiment largely as an exogenous event. This is justified because participants did not know in advance that there would be an experiment on cheating behavior. In fact, it seems plausible that participants in the study may differ in their characteristics, even with respect to allowing for or potentially aiming for attendants, or the opposite. In case of large differences between the groups of attendants and the roughly one-third of participants without attendants, these differences may be the drivers behind attendance and, thus, of interest for understanding cheating behavior.

Therefore, we form two groups regarding whether the experiment was conducted either (a) with attendants or (b) without attendants. First, we test whether these groups differ substantially in their characteristics. This is generally not the case (as shown in Table D.5) and the one borderline significant difference does not matter in economic terms.

Table D.5: Descriptive Statistics by the Presence of Attendants

\begin{tabular}{lccr}
\hline & Attendants & No Attendants & Difference \\
\hline Male & 0.34 & 0.35 & 0.01 \\
Age & 55.34 & 55.06 & -0.28 \\
Education & 5.26 & 5.69 & 0.43 \\
Consumption per Cap. & 7.09 & 7.09 & -0.00 \\
Asset Value & 8.07 & 8.29 & 0.22 \\
Risk Taking, MPL & 11.24 & 10.44 & -0.79 \\
Confidence & 2.48 & 2.32 & $-0.16^{*}$ \\
Trust in Outsiders & 1.62 & 1.58 & -0.04 \\
Perceived Corruption & 0.74 & 0.75 & 0.01 \\
\hline Observations & 328 & 185 & 513 \\
\hline
\end{tabular}

Variables: Attendants Dummy $(0=$ no attendants; $1=$ attendants $)$, Male $(0=$ female; $1=$ male $)$, Age(years $)$, Education(years), Consumption per Cap.(annually, in log US-Dollar), Asset Value(log total value of all hh assets), Risk Taking, MPL(switching row from lottery to safe value, from 1 to 21), Confidence(in agricultural decisions from 1-always confident to 5-never confident), Trust in Outsiders(1-trust them not at all to 5 -trust them a lot), Perceived Corruption( $0=$ no; $1=$ yes $)$.

$* \mathrm{p}<0.10,{ }^{* *} \mathrm{p}<0.05,{ }^{* * *} \mathrm{p}<0.01$

Thus, second, we run the main regressions as presented in Table 3 for these two subgroups. Results in Table D.6 show that the sign and size of coefficients is qualitatively similar to results in Table 3, although with some heterogeneity across groups. Moreover, 
the level of significance is lower, particularly for group (a), and accordingly the adjusted R-squared is several times higher for group (b) than for group (a). This may cautiously indicate that these participants feel freer in behaving according to their preferences while the situation of attendants observing the experimental outcome may lead to a moderated outcome. Interestingly, the effect of risk taking is larger in group (a) than for the general sample, possibly because these risk-tolerant participants are less afraid to be caught or seen as liars, but negative, albeit not significant, for group (b).

Table D.6: Sample Split by Attendants Dummy

\begin{tabular}{|c|c|c|c|c|c|c|}
\hline & Attendants & $\begin{array}{c}\text { No } \\
\text { Attendants }\end{array}$ & Attendants & $\begin{array}{c}\text { No } \\
\text { Attendants }\end{array}$ & Attendants & $\begin{array}{c}\text { No } \\
\text { Attendants }\end{array}$ \\
\hline \multirow[t]{2}{*}{ Perceived Corruption } & 0.042 & $0.556^{* *}$ & 0.003 & $0.418^{*}$ & 0.185 & $0.561^{* *}$ \\
\hline & $(0.189)$ & $(0.224)$ & $(0.188)$ & $(0.228)$ & $(0.185)$ & $(0.218)$ \\
\hline \multirow[t]{2}{*}{ Male } & 0.189 & -0.236 & 0.193 & -0.141 & & \\
\hline & $(0.195)$ & $(0.216)$ & $(0.192)$ & $(0.220)$ & & \\
\hline \multirow[t]{2}{*}{ Age } & -0.028 & $-0.213^{* * *}$ & -0.026 & $-0.205^{* * *}$ & -0.042 & $-0.235^{* * *}$ \\
\hline & $(0.048)$ & $(0.072)$ & $(0.046)$ & $(0.071)$ & $(0.043)$ & $(0.070)$ \\
\hline \multirow[t]{2}{*}{$\operatorname{Age}^{2}$} & 0.000 & $0.002^{* * *}$ & 0.000 & $0.002^{* * *}$ & 0.000 & $0.002^{* * *}$ \\
\hline & $(0.000)$ & $(0.001)$ & $(0.000)$ & $(0.001)$ & $(0.000)$ & $(0.001)$ \\
\hline \multirow[t]{2}{*}{ Education } & 0.039 & -0.022 & 0.054 & -0.014 & & \\
\hline & $(0.034)$ & $(0.039)$ & $(0.033)$ & $(0.036)$ & & \\
\hline \multirow[t]{2}{*}{ Consumption per Cap. } & -0.047 & 0.099 & & & & \\
\hline & $(0.160)$ & $(0.172)$ & & & & \\
\hline \multirow[t]{2}{*}{ Risk Taking, MPL } & $0.024^{* *}$ & -0.011 & $0.026^{* *}$ & -0.013 & & \\
\hline & $(0.011)$ & $(0.014)$ & $(0.011)$ & $(0.013)$ & & \\
\hline \multirow[t]{2}{*}{ Confidence } & -0.008 & 0.162 & -0.008 & $0.196^{*}$ & & \\
\hline & $(0.084)$ & $(0.110)$ & $(0.083)$ & $(0.110)$ & & \\
\hline \multirow[t]{2}{*}{ Trust in Outsiders } & $-0.183^{*}$ & 0.089 & -0.166 & 0.046 & & \\
\hline & $(0.107)$ & $(0.139)$ & $(0.106)$ & $(0.137)$ & & \\
\hline \multirow[t]{2}{*}{ Asset Value } & & & $-0.136^{* *}$ & 0.015 & & \\
\hline & & & $(0.063)$ & $(0.077)$ & & \\
\hline \multirow[t]{2}{*}{ Constant } & $2.787^{*}$ & $7.384^{* * *}$ & $3.460^{* *}$ & $7.854^{* * *}$ & $3.079 * * *$ & $8.741^{* * *}$ \\
\hline & $(1.539)$ & $(2.420)$ & $(1.385)$ & $(2.119)$ & (1.130) & (1.948) \\
\hline Observations & 299 & 172 & 299 & 172 & 302 & 173 \\
\hline Adj. R-Squared & 0.023 & 0.094 & 0.041 & 0.074 & 0.000 & 0.095 \\
\hline
\end{tabular}

Indep. Variables: Perceived Corruption $(0=$ no; $1=$ yes $)$, Male $(0=$ female; $1=$ male $)$, Age(years), Education(years), Consumption per Cap.(annually, in log US-Dollar), Risk Taking, MPL(switching row from lottery to safe value, from 1 to 21), Confidence(in agricultural decisions from 1-always confident to 5-never confident), Trust in Outsiders, Asset Value(log total value of all hh assets). S.E. in parentheses.

${ }^{*} \mathrm{p}<0.10,{ }^{* *} \mathrm{p}<0.05,{ }^{* * *} \mathrm{p}<0.01$ 